Article

\title{
Interaction between Saikosaponin D, Paeoniflorin, and Human Serum Albumin
}

\author{
Guo-Wu Liang ${ }^{1,+}$, Yi-Cun Chen ${ }^{2,+}$, Yi Wang ${ }^{1}$, Hong-Mei Wang ${ }^{1}$, Xiang-Yu Pan ${ }^{1}$, \\ Pei-Hong Chen ${ }^{2}$ and Qing-Xia Niu ${ }^{1, *}$ \\ 1 Department of Pathophysiology, Key Immunopharmacology Laboratory, \\ Institute of Inflammation and Immune Diseases, Shantou University Medical College, \\ Shantou 515000, China; gwliangizzy@163.com (G.-W.L.); posywy@163.com (Y.W.); \\ junebulu@163.com (H.-M.W.); fxmdp9@163.com (X.-Y.P.) \\ 2 Department of Pharmacology, Traditional Chinese Medicine Laboratory, \\ Shantou University Medical College, Shantou 515000, China; \\ chenyicun@yeah.net (Y.-C.C.); ph553253347@163.com (P.-H.C.) \\ * Correspondence: qxniu@stu.edu.cn; Tel.: +86-754-8890-0380; Fax: +86-0754-8890-0192 \\ + These authors contributed equally to this work.
}

Received: 23 December 2017; Accepted: 22 January 2018; Published: 27 January 2018

\begin{abstract}
Saikosaponin D (SSD) and paeoniflorin (PF) are the major active constituents of Bupleuri Radix and Paeonia lactiflora Pall, respectively, and have been widely used in China to treat liver and other diseases for many centuries. We explored the binding of SSD/PF to human serum albumin (HSA) by using fluorospectrophotometry, circular dichroism (CD) and molecular docking. Both SSD and PF produced a conformational change in HSA. Fluorescence quenching was accompanied by a blue shift in the fluorescence spectra. Co-binding of PF and SSD also induced quenching and a conformational change in HSA. The Stern-Volmer equation showed that quenching was dominated by static quenching. The binding constant for ternary interaction was below that for binary interaction. Site-competitive experiments demonstrated that SSD/PF bound to site I (subdomain IIA) and site II (subdomain IIIA) in HSA. Analysis of thermodynamic parameters indicated that hydrogen bonding and van der Waals forces were mostly responsible for the binary association. Also, there was energy transfer upon binary interaction. Molecular docking supported the experimental findings in conformation, binding sites and binding forces.
\end{abstract}

Keywords: saikosaponin; paeoniflorin; human serum albumin; spectroscopy; molecular docking

\section{Introduction}

Human serum albumin (HSA), a non-glycosylated single polypeptide chain (585 amino acid residues, $66500 \mathrm{Da}$ ) with $\alpha$-helical secondary and a heart-shaped tertiary structure, accounts for about $60 \%$ of the total plasma protein, with a concentration of $0.05 \mathrm{~g} / \mathrm{mL}$ in the bloodstream $[1,2]$. As a carrier, the protein acts to combine, transport and distribute a variety of endogenous and exogenous substances, such as metabolites, neurotransmitters, amino acids, hormones and drugs [3]. Radix Bupleuri (Chai Hu in Chinese) is derived from the dried roots of Bupleurum chinense DC. and Bupleurum scorzonerifolium Willd. Chai Hu contains many pharmacological ingredients, such as volatile oils, triterpenoid saponins, and flavonoids [4,5]. Among the triterpenoid saponins, which are the major active components of Chai $\mathrm{Hu}$, the action of saikosaponin D (SSD, CAS Registry Number: 20874-52-6, Figure 1) is considered to be strongest. Following oral administration of Bupleurum dropping pills, $\mathrm{C}_{\max }, \mathrm{T}_{\max }$ and $\mathrm{t}_{1 / 2}$ of SSD in plasma of rats has been determined to be $3.93 \pm 2.74 \mathrm{ng} / \mathrm{mL}, 0.33 \pm 0.20 \mathrm{~h}$, and $3.27 \pm 1.78 \mathrm{~h}$, respectively [6]. Recent studies report that SSD possesses anti-oxidative, anti-inflammatory and anti-fibrotic properties, and promotes apoptosis 
of hepatic stellate cells [7-11]. Paeonia lactiflora Pall (Shao Yao in Chinese) has widely been used in China for many centuries to treat many diseases, such as pyretic, allergic, and inflammatory disorders. Paeoniflorin (PF, CAS Registry Number: 23180-57-6, Figure 1), a water-soluble monoterpene glycoside, is purified from the dried root of Shao Yao. After oral administration of $\mathrm{PF}$ to rats, the $\mathrm{C}_{\max }$, $\mathrm{T}_{\max }$ and $\mathrm{t}_{1 / 2}$ of $\mathrm{PF}$ in plasma has been reported to be $809.16 \pm 163.75 \mathrm{ng} / \mathrm{mL}, 14.65 \pm 1.20 \mathrm{~min}$, and $174.60 \pm 94.52 \mathrm{~min}$ [12]. As a major compound of Shao Yao, PF efficiently alleviates oxidative damage in HUVECs via the ROS-HIF- $1 \alpha$ /VEGF pathway, liver fibrosis by the HIF- $1 \alpha / \mathrm{mTOR}$ signaling pathway, non-alcoholic fatty liver disease through multiple signaling pathways, and inflammatory response in ulcerative colitis via inhibiting the MAPK/NF- $\mathrm{KB}$ pathway and apoptosis in mice [13-16].
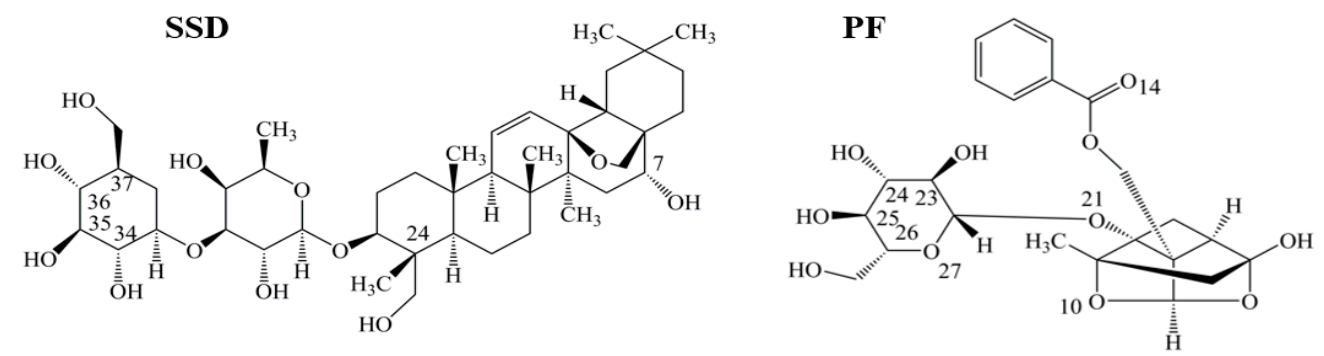

Figure 1. Chemical structures of saikosaponin D (SSD, $\mathrm{C}_{42} \mathrm{H}_{68} \mathrm{O}_{13}, \mathrm{MW780.99)}$ ) and paeoniflorin $\left(\mathrm{PF}, \mathrm{C}_{23} \mathrm{H}_{28} \mathrm{O}_{11}\right.$, MW480.46), numbered with ChemDraw software.

The pharmacological activity of drugs is influenced by how they are interact with HSA and other target molecules in different tissues $[17,18]$. Little information on the co-binding of PF and SSD to HSA is available, although Chai $\mathrm{Hu}$ and Bai Shao have together been used for centuries in China and other Asian countries for liver diseases, gynecological diseases, and other diseases. Thus, the investigation of the binding between SSD/PF and HSA is of important significance in life sciences, chemistry, and medicine [19-23]. A previous study reported that PF alone at high concentrations binds HSA [24]. The present study is focused on the binding of SSD and PF at low concentrations with HSA. By comparison, there is a considerable difference in spectra, binding sites, and thermodynamic parameters of HSA induced by PF at low and high concentrations.

\section{Results and Discussion}

\subsection{SSD- and PF-Induced Conformational Changes in HSA}

\subsubsection{Fluorescence Spectra}

HSA itself has endogenous fluorescence, primarily resulting from tyrosine and tryptophan residues. According to a previous report and our experiments, an excitation wavelength of $280 \mathrm{~nm}$ was employed $[25,26]$. As shown in Figure 2 and Table 1, examination of fluorescence peaks revealed a $5 \mathrm{~nm}$ blue shift for HSA following binding to SSD, and a $3 \mathrm{~nm}$ blue shift for HSA following PF binding. Unlike to these findings, a blue shift for HSA-PF at high-dose binding was not reported [24]. Although the SSD-induced shift was slightly greater to that of the PF-induced shift, this suggests that SSD and PF both induce conformational changes in HSA. Further, synchronous fluorescence measurements were performed to investigate that the two residues play a role in the fluorescence of HSA. A $\Delta \lambda=15 \mathrm{~nm}$ or $\Delta \lambda=60 \mathrm{~nm}$ is characteristic of the fluorescence spectra for tyrosine or tryptophan residues, respectively. A blue micro-shift of $2 \mathrm{~nm}$ in fluorescence peaks was observed at $\Delta \lambda=60 \mathrm{~nm}$ in HSA-SSD and HSA-PF binding, whereas there was no $\Delta \lambda=15$ shift of peaks in the two binary binding. We then examined the interaction among the three components in a ternary reaction. As for HSA-PF-SSD binding, following the addition of PF at a fixed dose, titration with SSD induced a blue shift of $13 \mathrm{~nm}$ in the fluorescence peaks of HSA. As for HSA-SSD-PF binding, following the addition of SSD at a fixed dose, titration with PF only induced a slight blue shift of fluorescence spectra. It is interesting that the shift induced 
by HSA-PF-SSD binding was significantly above that induced by HSA-SSD plus HSA-PF binding, whereas the shift induced by HSA-SSD-PF binding was smaller than that induced by HSA-SSD plus HSA-PF binding. This indicates that SSD can greatly promote PF-induced conformational change of HSA, whereas PF has little effect on SSD-induced conformational change. This could be due to differences in binding affinity between HSA-SSD and HSA-PF. In short, the results indicate that the interaction between HSA and SSD/PF perturbs the microenvironment surrounding tryptophan.
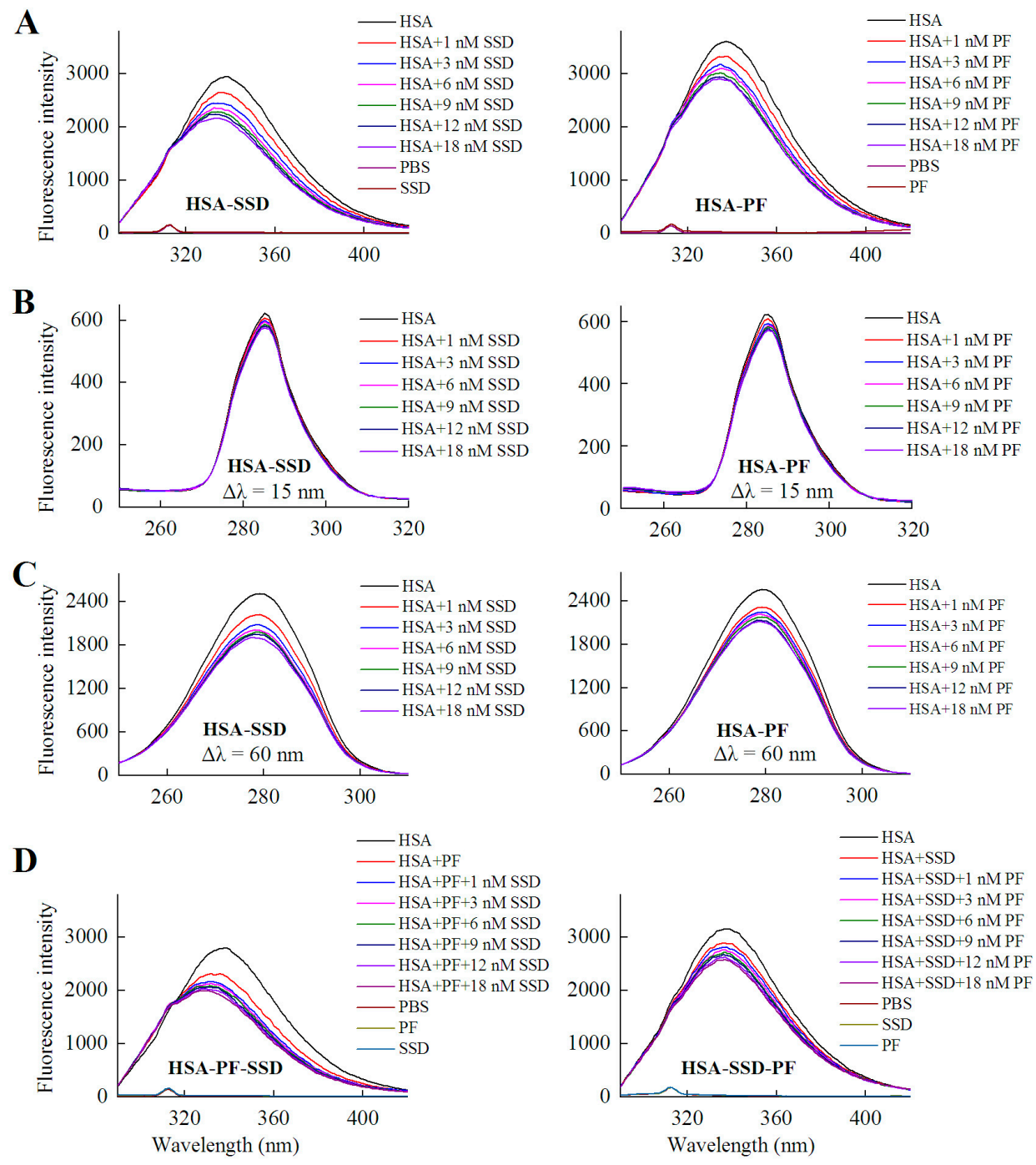

Figure 2. Fluorescence spectra of HSA in the presence of SSD and PF. Both conventional (A, D) and synchronous fluorescence measurements $(\mathbf{B}, \mathbf{C})$ were performed at $30^{\circ} \mathrm{C}$. $\mathrm{C}_{\mathrm{HSA}}=1 \mu \mathrm{M}$; in the ternary binding studies: $\mathrm{C}_{\mathrm{PF}}=3 \mu \mathrm{M} ; \mathrm{C}_{\mathrm{SSD}}=3 \mu \mathrm{M}$; HSA, human serum albumin; PF, paeoniflorin; SSD, saikosaponin $\mathrm{D} ; \Delta \lambda=15 \mathrm{~nm}$ or $\Delta \lambda=60 \mathrm{~nm}$ for tyrosine and tryptophan residues, respectively.

The shifts in the fluorescence peaks of HSA are closely related to conformational changes of the protein. A blue shift indicates that the hydrophobicity of amino acid residues increases in the microenvironment surrounding the fluorophores, and the structure of the HSA hydrophobic cavity becomes closer [27]. Therefore, the conformation of HSA is changed by binding to SSD and PF, individually and combined, and tryptophan residues are likely involved in the binding reaction [28].

As shown in Figure 3, fluorescence spectra of HSA were recorded for PF at 0-30 $\mu \mathrm{M}$. It is worth noting that the fluorescence intensity did not decline, but rather significantly increased with the addition of PF. The peak appearance of HSA shifted to blue wavelengths although a blue shift at 
maximum emission was not observed. At $\Delta \lambda=60 \mathrm{~nm}$, a blue shift of $5 \mathrm{~nm}$ (from 278 to $273 \mathrm{~nm}$ ) formed at maximum emission. Undoubtedly, the difference between the present and reported study is mainly attributed to the concentration of PF [24]. These findings reveal that the amino acid residues in the vicinity of the fluorophore are disturbed by PF at both low and high concentrations. Therefore, PF at low concentrations ranging from 1 to $18 \mathrm{nM}$ was employed in further study.

Table 1. Alternation of HSA fluorescence spectra.

\begin{tabular}{ccccc}
\hline Type & Binding & Detection & Shift and Its Range (nm) & Quenching (\%) \\
\hline \multirow{5}{*}{ Binary } & & $\lambda e x=280 \mathrm{~nm}$ & Left shift 5, 338-333 & 26.55 \\
& HSA-SSD & $\Delta \lambda=15 \mathrm{~nm}$ & No shift & 7.43 \\
& & $\Delta \lambda=60 \mathrm{~nm}$ & Left shift 2, 279-277 & 24.34 \\
\cline { 2 - 5 } & & $\lambda \mathrm{ex}=280 \mathrm{~nm}$ & Left shift 3, 337-334 & 19.42 \\
& HSA-PF & $\Delta \lambda=15 \mathrm{~nm}$ & No shift & 8.29 \\
& $\Delta \lambda=60 \mathrm{~nm}$ & Left shift 2, 279-277 & 17.66 \\
\hline \multirow{2}{*}{ Terniary } & HSA-PF-SSD & $\lambda \mathrm{ex}=280 \mathrm{~nm}$ & Left shift 13, 339-326 & 28.63 \\
& HSA-SSD-PF & $\lambda \mathrm{ex}=280 \mathrm{~nm}$ & Left shift 3, 336-333 & 18.19 \\
\multirow{2}{*}{ Tyrosine } & Tyr-SSD & $\Delta \lambda=15 \mathrm{~nm}$ & No shift & 2.82 \\
& Tyr-PF & $\Delta \lambda=15 \mathrm{~nm}$ & No shift & 4.31 \\
\hline \multirow{2}{*}{ Tryptophan } & Trp-SSD & $\Delta \lambda=60 \mathrm{~nm}$ & No shift & 12.82 \\
& Trp-PF & $\Delta \lambda=60 \mathrm{~nm}$ & No shift & 10.38 \\
\hline
\end{tabular}
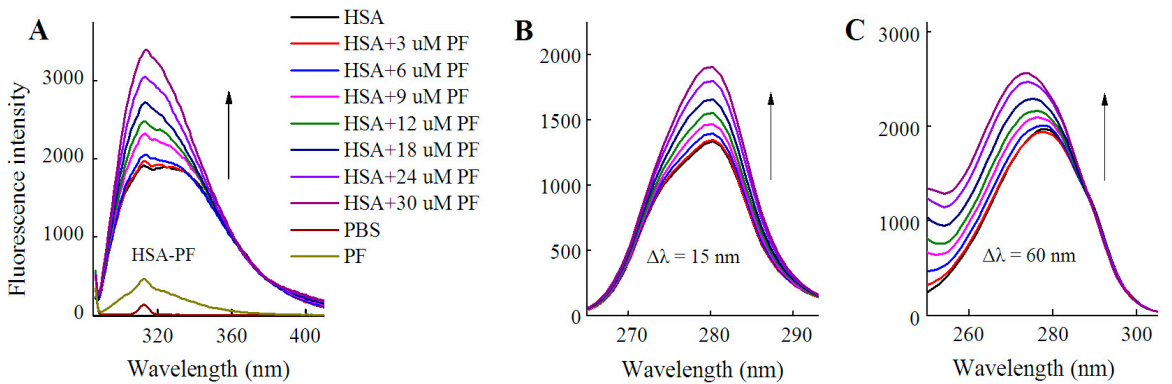

Figure 3. Fluorescence spectra of HSA in the presence of PF at 3-30 $\mu \mathrm{M}$. Both conventional (A) and synchronous fluorescence measurements $(\mathbf{B}, \mathbf{C})$ were performed at $20^{\circ} \mathrm{C}$. $\mathrm{C}_{\mathrm{HSA}}=1 \mu \mathrm{M} ; \mathrm{C}_{\mathrm{PF}}=0$ (black), 3 (red); 6 (blue), 9 (pink), 12 (green), 18 (dark blue), 24 (purple), and $30 \mu \mathrm{M}$ (brown), respectively.

In order to investigate if a direct interaction is involved between the two drugs and tyrosine/tryptophan, the corresponding fluorescence measurements were carried out. In line with the quenching effect of both SSD and PF on HSA at $\Delta \lambda=15 \mathrm{~nm}$ and $\Delta \lambda=60 \mathrm{~nm}$ (Table 1), the results of the direct interaction support that tryptophan mainly contributed to the binding reaction (Table 1 , Figure 4). Similarly, paeonol, a phenolic compound also derived from the paeony, was found to have direct competition with L-tryptophan [29].

\subsubsection{Circular Dichroism Studies}

Circular dichroism (CD) was employed in order to confirm whether SSD or PF evokes a conformational change in HSA. HSA showed a negative absorption at 209 and $220 \mathrm{~nm}$, consistent with a previous report [30]. The results can be calculated with the following equations [30]:

$$
\begin{gathered}
\text { MRE }=\frac{C D(\text { mdeg })}{10 C_{p} n l} \\
\alpha-\operatorname{helix}(\%)=\frac{-(M R E)_{209}-4000 C D(m \mathrm{deg})}{33000-4000} \times 100
\end{gathered}
$$



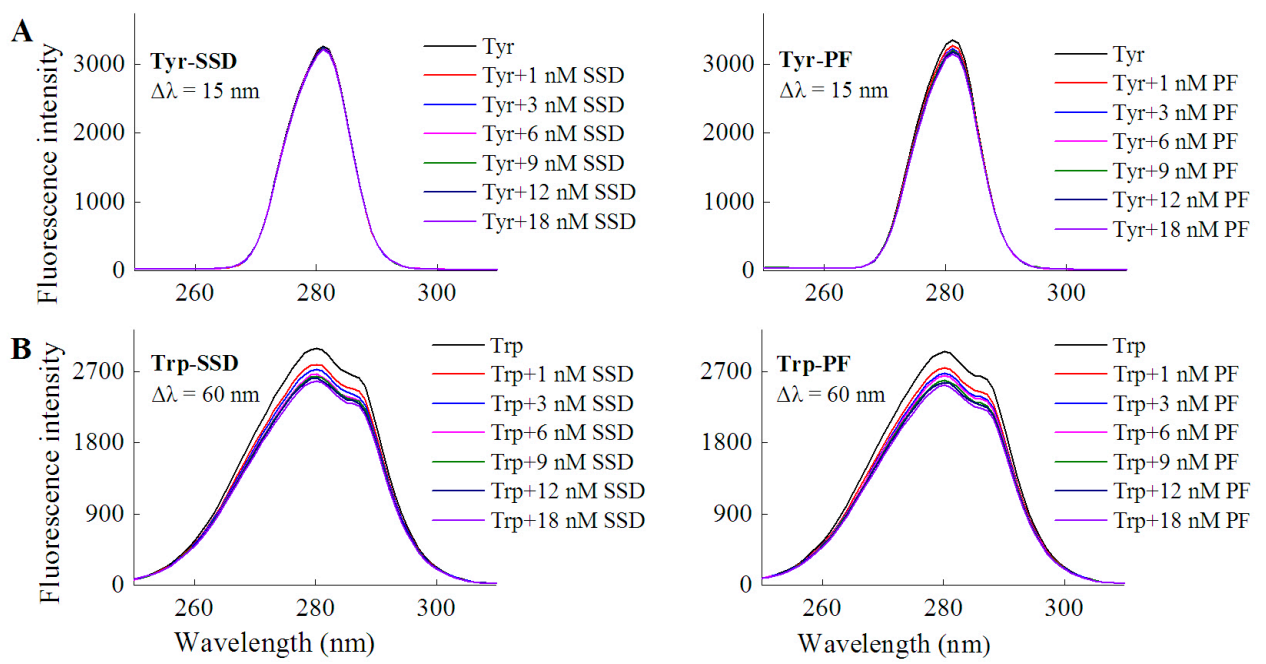

Figure 4. Fluorescence spectra of L-tyrosine (A) or L-tryptophan (B) in the presence of SSD/PF. Tyr, L-tyrosine ; Trp, L-tryptophan; $\mathrm{C}_{\mathrm{Tyr}}=10 \mu \mathrm{M} ; \mathrm{C}_{\mathrm{Trp}}=10 \mu \mathrm{M}$.

Here, $M R E, C_{p}, n$ and $l$ represent the mean residue ellipticity, the concentration of HSA, the number of amino acid residues and the path length, respectively. In Equation (2), 33,000 and 4000 represent the $M R E$ values of a pure $\alpha$-helix and a $\beta$-form with random coil conformation at $209 \mathrm{~nm}$, respectively.

As shown in Figure 5 and Table 2, SSD perturbed $\alpha$-helices and $\beta$-turns, while it had little effect on $\beta$-sheets and random coils. In PF-HSA binding, PF at $1 \mu \mathrm{M}$ slightly increased the $\alpha$-helical content. On the contrary, PF at $25 \mu \mathrm{M}$ slightly decreased the $\alpha$-helical content, as previously shown [24]. In short, PF alone has a little effect on the helical structure of HSA. However, for ternary binding, the $\alpha$-helical content increased significantly. Obvious differences were found between the binary and ternary complexes, suggesting that there is an additive effect of SSD and PF. These results are in agreement with those obtained from the investigations on HSA fluorescence spectra, further illustrating that HSA conformation is altered by SSD and PF.

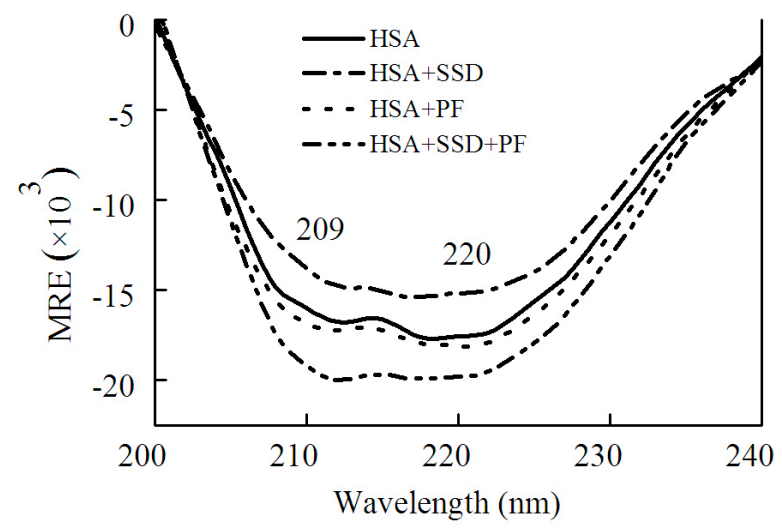

Figure 5. CD spectra of HSA in the absence and presence of SSD or PF.

Table 2. Percentages of secondary structure before and after binding between HSA and SSD/PF.

\begin{tabular}{cccccc}
\hline Binding & Ratio & $\alpha$-Helix & $\beta$-Sheet & $\beta$-Turn & Random Coil \\
\hline HSA & & 52.7 & 7.3 & 10.9 & 29.3 \\
HSA-SSD & $1: 1$ & 46.3 & 9.0 & 16.9 & 27.8 \\
HSA-PF & $1: 1$ & 55.6 & 6.5 & 9.1 & 25.2 \\
HSA-PF-SSD & $1: 1: 1$ & 66.4 & 5.0 & 8.6 & 20.1 \\
\hline
\end{tabular}




\subsection{Fluorescence Quenching of HSA by SSD and PF}

As for HSA fluorescence intensity, our findings are consistent with prior studies showing the fluorescence of $1.5 \mu \mathrm{M}$ HSA is about 4000 [31]. However, the fluorescence of $1 \mu \mathrm{M}$ HSA in the present study was much above that $(<1200)$ of $10 \mu \mathrm{M}$ HSA [24]. This significant difference may mainly be ascribed to HSA itself, set-up of parameter measurements, sensitivity of light, filter, or detector, reaction system, and experimental conditions. As shown in Figure 2 and Table 1, the fluorescence intensity of HSA decreased with the increase in SSD or PF concentration. The percentage of synchronous fluorescence quenching at $\Delta \lambda=60 \mathrm{~nm}$ was clearly above that at $\Delta \lambda=15 \mathrm{~nm}$. The direct interaction between the two drugs and tryptophan showed that the quenching effect at $\Delta \lambda=60 \mathrm{~nm}$ was stronger than that at $\Delta \lambda=15 \mathrm{~nm}$ (Figure 4 and Table 1), supporting that tryptophan is mainly responsible for the fluorescence quenching of HSA. In contrast, the quenching of HSA at $\Delta \lambda=60 \mathrm{~nm}$ induced by PF was a bit lower than that induced by SSD, which may suggest that HSA-SSD binding can exert a slightly stronger effect on tryptophan than HSA-PF binding.

\subsection{Static Quenching of HSA Induced by SSD and PF}

Fluorescence quenching takes place by two mechanisms, dynamic quenching and static quenching. Dynamic quenching is unaffected by the structure and bioactivity of the protein, and depends on intermolecular collision between the quencher and the fluorescent molecule at an excited state. Static quenching, which forms a new composite, is due to the intramolecular interaction of quenchers with fluorescent molecules at a ground state [32]. In order to probe the mechanism of SSD- and PF-mediated quenching, the Stern-Volmer equation was employed [25]:

$$
F_{0} / F=1+K_{\mathrm{q}} \tau_{0}[Q]=1+K_{S V}[Q]
$$

Here, $F_{0}$ and $F$ denote the fluorescence intensities in the absence and presence of SSD or PF, respectively. $[Q]$ is for the concentration of SSD or PF. $K_{\mathrm{sv}}$, the Stern-Volmer quenching constant, reflects the degree of quencher contact with fluorescent molecules and reaction speed. The value of $\tau_{0}$, the average lifetime of fluorescent molecules, in the absence of quencher, is generally about $10^{-8} \mathrm{~s} . K_{\mathrm{q}}$, the apparent bimolecular quenching rate constant. For the biomacromolecule, the maximum $K_{\mathrm{q}}$ value of most quenchers is $2.0 \times 10^{10} \mathrm{~L} \cdot \mathrm{mol}^{-1} \cdot \mathrm{s}^{-1}$ [25].

As shown in Table 3, the $K_{\mathrm{q}}$ at both $20^{\circ} \mathrm{C}$ and $30^{\circ} \mathrm{C}$ was much above $2.0 \times 10^{10} \mathrm{~L} \cdot \mathrm{mol}^{-1} \cdot \mathrm{s}^{-1}$, which indicates that SSD and PF induce static quenching. In ternary interaction, similar results occurred. Accordingly, Stern-Volmer plots for both binary and ternary interaction show that there is a good linear relationship between the concentration of drugs and the value of $F_{0} / F$, confirming that static quenching of HSA can be induced by SSD or PF (Figure 6). In PF-HSA binding, it is interesting that the $K_{\mathrm{q}}$ induced by PF at $1-18 \mathrm{nM}\left(\sim 1 \times 10^{15}\right)$ was much above that induced by PF at $2.5-12.5 \mu \mathrm{M}$ $\left(\sim 1 \times 10^{12}\right)$ [24]. This is most likely due the fact that PF at high concentrations produces more complex effects because more amino acid residues are perturbed.

Table 3. Stern-Volmer quenching reactive constants.

\begin{tabular}{cccccc}
\hline Binding & Fluorescence & $\mathbf{T}\left({ }^{\circ} \mathbf{C}\right)$ & Detection & Kq $\left(\mathbf{L} \cdot \mathbf{m o l}^{-\mathbf{1}} \cdot \mathbf{s}^{\mathbf{- 1}}\right)$ & $\mathbf{R}$ \\
\hline \multirow{4}{*}{ Conventional } & 20 & $\lambda \mathrm{ex}=280 \mathrm{~nm}$ & $1.6 \times 10^{15}$ & 0.998 \\
& 30 & $\lambda \mathrm{ex}=280 \mathrm{~nm}$ & $1.1 \times 10^{15}$ & 0.996 \\
\cline { 2 - 5 } HSA-SSD & & $\Delta \lambda=15 \mathrm{~nm}$ & $4.3 \times 10^{14}$ & 0.991 \\
& \multirow{2}{*}{ Synchronous } & 20 & $\Delta \lambda=60 \mathrm{~nm}$ & $1.3 \times 10^{15}$ & 0.994 \\
& & 30 & $\Delta \lambda=15 \mathrm{~nm}$ & $3.5 \times 10^{14}$ & 0.993 \\
& 30 & $\Delta \lambda=60 \mathrm{~nm}$ & $1.1 \times 10^{15}$ & 0.991 \\
\hline
\end{tabular}


Table 3. Cont.

\begin{tabular}{|c|c|c|c|c|c|}
\hline Binding & Fluorescence & $\mathrm{T}\left({ }^{\circ} \mathrm{C}\right)$ & Detection & $\mathrm{Kq}\left(\mathrm{L} \cdot \mathrm{mol}^{-1} \cdot \mathrm{s}^{-1}\right)$ & $\mathbf{R}$ \\
\hline \multirow{6}{*}{ HSA-PF } & \multirow{2}{*}{ Conventional } & 20 & $\lambda \mathrm{ex}=280 \mathrm{~nm}$ & $1.3 \times 10^{15}$ & 0.995 \\
\hline & & 30 & $\lambda \mathrm{ex}=280 \mathrm{~nm}$ & $1.1 \times 10^{15}$ & 0.993 \\
\hline & \multirow{4}{*}{ Synchronous } & 20 & $\Delta \lambda=15 \mathrm{~nm}$ & $7.5 \times 10^{13}$ & 0.992 \\
\hline & & 20 & $\Delta \lambda=60 \mathrm{~nm}$ & $7.0 \times 10^{13}$ & 0.992 \\
\hline & & 30 & $\Delta \lambda=15 \mathrm{~nm}$ & $3.2 \times 10^{14}$ & 0.994 \\
\hline & & 30 & $\Delta \lambda=60 \mathrm{~nm}$ & $5.8 \times 10^{14}$ & 0.995 \\
\hline \multirow{2}{*}{ HSA-PF-SSD } & \multirow{2}{*}{ Conventional } & 20 & $\lambda \mathrm{ex}=280 \mathrm{~nm}$ & $8.5 \times 10^{14}$ & 0.992 \\
\hline & & 30 & $\lambda \mathrm{ex}=280 \mathrm{~nm}$ & $7.3 \times 10^{14}$ & 0.994 \\
\hline \multirow{2}{*}{ HSA-SSD-PF } & \multirow{2}{*}{ Conventional } & 20 & $\lambda \mathrm{ex}=280 \mathrm{~nm}$ & $5.9 \times 10^{14}$ & 0.992 \\
\hline & & 30 & $\lambda \mathrm{ex}=280 \mathrm{~nm}$ & $6.8 \times 10^{14}$ & 0.993 \\
\hline
\end{tabular}

$\mathrm{R}$, linear correlation coefficient.

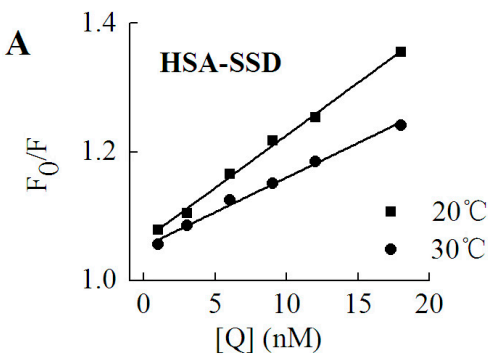

B
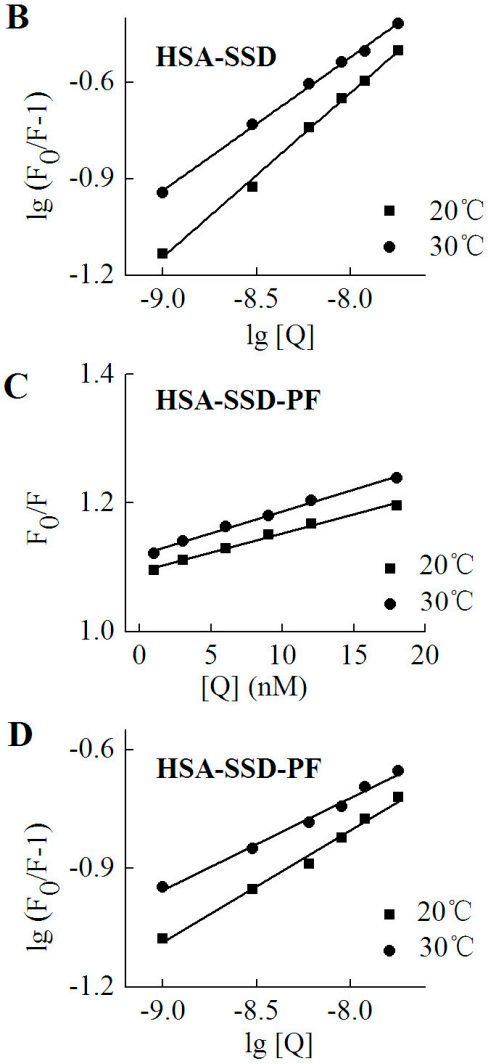
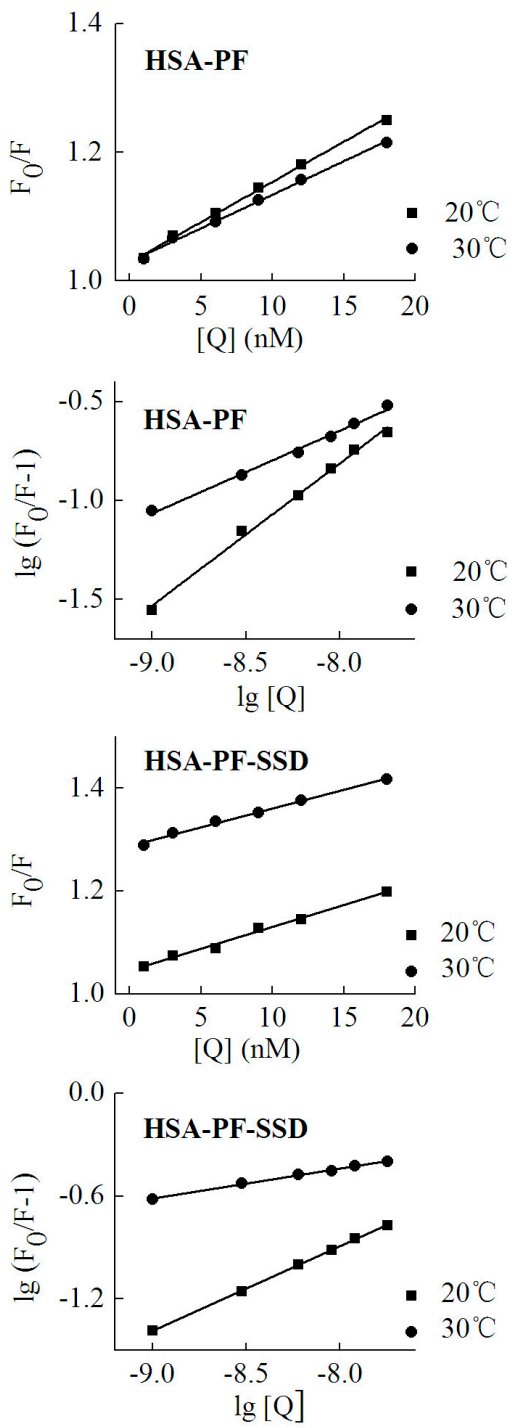

Figure 6. Stern-Volmer plots for HSA-SSD and -PF interaction. Experiments were performed in Figure 2. $(\mathbf{A}, \mathbf{C})$ are for Stern-Volmer plots. (B,D) represent double logarithmic plots for $\lg \left(\mathrm{F}_{0} / \mathrm{F}-1\right)$ vs. $\lg [\mathrm{Q}]$. $\mathrm{F}_{0}$, HSA fluorescence intensities without the quencher; F, HSA fluorescence intensities with the quencher. [Q] denotes SSD or PF at doses of $0,1,3,6,9,12$ and $18 \mathrm{nM}$, respectively. 


\subsection{Binding Constants, Sites and Forces}

\subsubsection{Binding Constants and Numbers of Binding Sites}

For static quenching, the binding constant and number of binding sites can be calculated by Equation (4) [25]:

$$
\lg \left(F_{0} / F-1\right)=\lg K_{a}+n \lg [Q]
$$

The binding constant $\left(K_{a}\right)$ is a characteristic parameter that reflects the fastness between drug and the protein. The $K_{a}$ for low affinity binding is lower than $10^{3} \mathrm{~mol} \cdot \mathrm{L}^{-1}$ [26,32]. As shown in Table 4 , there was a weak interaction between both HSA and SSD/PF. The resulting $K_{a}$ value and the number of binding sites $(n)$ at $30{ }^{\circ} \mathrm{C}$ were below that at $20{ }^{\circ} \mathrm{C}$, which is perhaps due to higher temperatures resulting in molecular diffusion and the dissociation of weakly bound complexes. The $K_{a}$ declined with increasing temperature, indicating that temperature is a major factor influencing the $K_{a}$. A $K_{a}$ for low affinity binding is helpful for releasing the drug from the conjugates in target tissues, which affects the free fraction of the drugs to promote the drug effects [33]. Similar to our present study, HSA binding to PF or paeonol in previous studies also show a $K_{a}$ of $10^{3} \sim 10^{4}$ (Table 5). SSC is also, a triterpenoid saponin derived from Chai Hu. The $K_{a}$ of SSC with HSA is also on the order of $10^{3}$, in line with SSD (Table 5). In ternary binding, the $K_{a}$ and the number of binding sites in the ternary interaction were below those in binary binding, suggesting that release of the drugs is easier upon ternary interaction than upon binary interaction.

Table 4. SSD- and PF-induced binding reaction parameters of HSA.

\begin{tabular}{ccccc}
\hline Binding & $\mathbf{T}\left({ }^{\circ} \mathbf{C}\right)$ & $\boldsymbol{K}_{\boldsymbol{a}}\left(\mathbf{m o l} \cdot \mathbf{L}^{-\mathbf{1}}\right) \pm \mathbf{S D}$ & $\boldsymbol{n}$ & $\mathbf{R}$ \\
\hline \multirow{2}{*}{ HSA-SSD } & 20 & $6.54 \times 10^{3} \pm 0.146$ & 0.525 & 0.998 \\
& 30 & $8.28 \times 10^{2} \pm 0.015$ & 0.464 & 0.998 \\
\hline \multirow{2}{*}{ HSA-PF-SSD } & 20 & $2.46 \times 10^{3} \pm 0.138$ & 0.497 & 0.996 \\
& 30 & $0.95 \times 10^{2} \pm 0.121$ & 0.230 & 0.996 \\
\hline \multirow{2}{*}{ HSA-PF } & 20 & $7.39 \times 10^{4} \pm 0.174$ & 0.736 & 0.998 \\
& 30 & $4.43 \times 10^{3} \pm 0.019$ & 0.482 & 0.995 \\
\hline \multirow{2}{*}{ HSA-SSD-PF } & 20 & $9.58 \times 10^{2} \pm 0.024$ & 0.324 & 0.992 \\
& 30 & $3.24 \times 10^{2} \pm 0.031$ & 0.263 & 0.991 \\
\hline
\end{tabular}

$K_{a}$, binding constant; $n$, the number of binding sites; $\mathrm{R}$, linear correlation coefficient; SD, standard deviation.

Table 5. SSD/PF-related compound Ka and thermodynamic parameters.

\begin{tabular}{|c|c|c|c|c|c|c|c|c|}
\hline Drug & ${ }^{\circ} \mathrm{C}$ & $K_{a}$ & $n$ & $\Delta G$ & $\Delta S$ & $\Delta H$ & Reaction System & Reference \\
\hline PF & $\begin{array}{l}25 \\
37\end{array}$ & $\begin{array}{l}3.56 \times 10^{4} \\
3.78 \times 10^{4}\end{array}$ & $\begin{array}{l}0.62 \\
0.61\end{array}$ & $\begin{array}{l}-21.0 \\
-22.0\end{array}$ & 103.5 & 4.1 & $\begin{array}{l}\text { 10-70 } \mu \mathrm{M} \text { PF, } 10 \mu \mathrm{M} \\
\text { BSA, pH7.4 Tris-HCL }\end{array}$ & [34] \\
\hline PF & $\begin{array}{l}15 \\
37\end{array}$ & $\begin{array}{l}1.91 \times 10^{3} \\
1.42 \times 10^{3}\end{array}$ & $\begin{array}{l}0.91 \\
0.89\end{array}$ & $\begin{array}{l}-18.1 \\
-18.7\end{array}$ & 28.2 & -10.0 & $\begin{array}{l}\text { 2.5-12.5 } \mu \mathrm{M} \text { PF, } 10 \mu \mathrm{M} \\
\text { BHSA, pH7.4 Tris-HCL }\end{array}$ & [24] \\
\hline Paeonol & $\begin{array}{l}10 \\
40\end{array}$ & $\begin{array}{l}1.58 \times 10^{4} \\
9.68 \times 10^{2}\end{array}$ & $\begin{array}{l}1.01 \\
0.84\end{array}$ & $\begin{array}{l}-22.7 \\
-17.9\end{array}$ & $\begin{array}{l}88.7 \\
64.9\end{array}$ & 2.4 & $\begin{array}{l}\text { 10-70 } \mu \mathrm{M} \text { paenol, } 1 \mu \mathrm{M} \\
\text { BHSA, pH7.4 Tris-HCL }\end{array}$ & [35] \\
\hline Paeonol & $\begin{array}{c}4 \\
37 \\
\end{array}$ & $\begin{array}{l}1.33 \times 10^{4} \\
3.55 \times 10^{3}\end{array}$ & $\begin{array}{l}- \\
-\end{array}$ & $\begin{array}{l}-22.0 \\
-21.8\end{array}$ & -6.3 & -23.8 & pH7.4 PBS & [28] \\
\hline SSC & 26 & $3.72 \times 10^{3}$ & 0.79 & -20.34 & -90.3 & -47.3 & $\begin{array}{l}1-15 \mu \mathrm{M} \text { PF, } 2 \mu \mathrm{M} \\
\text { BHSA, pH7.4 PBS }\end{array}$ & [26] \\
\hline
\end{tabular}

\subsubsection{Identification of SSD or PF Binding Sites}

HSA has three homologous domains (I, II, and III): I (residues 1-195), II (196-383), and III (384-585). Each domain contains two subdomains, A and B, which consist of a hydrophobic cavity. Subdomain IIA and IIIA are also called Sudlow I (site I) and Sudlow II (site II), respectively. Site I gives priority to 
binding with heterocyclic ligands, such as warfarin. Site II more actively binds indole and aromatic compounds, such as ibuprofen [36]. Warfarin and ibuprofen are routinely used to probe sites I and II, respectively [37]. As shown in Figure 7 and Table 6, quenching of HSA fluorescence intensity by about $20 \%$ and a blue shift were also observed in all groups. When the concentration of the probe was fixed, the shift induced by HSA-warfarin-SSD or HSA-ibuprofen-SSD mixtures was consistent with the HSA-SSD control, while the shift induced by HSA-warfarin-PF or HSA-ibuprofen-PF mixtures was consistent with the HSA-PF control, which suggests that the probe likely has little effect on the conformational changes of binary binding. When the concentration of SSD/PF is fixed, the shift displayed by the HSA-SSD/PF-probe mixture was consistent with HSA-probe control, suggesting that the probe also exerted little effect on the conformational changes of binary binding.

Among the binary reactions, the $K_{a}$ for HSA-PF binding was the highest. The $K_{a}$ for the binding of HSA to warfarin or ibuprofen was $2.54 \times 10^{2}$ and $4.10 \times 10^{2}$, respectively, which is significantly lower than that of the previous report, for micromolar levels of warfarin or ibuprofen, that the $K_{a}$ values for binding to albumin were $3.4 \times 10^{5}$ and $3.5 \times 10^{6}$, respectively [38]. The difference may be associated with employed methods, drug concentration, reaction system, and experimental conditions. At a fixed concentration of the probe, the $K_{a}$ of HSA-warfarin/ibuprofen-SSD was significantly lower than that of the HSA-SSD/PF mixtures. At a fixed concentration of SSD/PF, the $K_{a}$ of the HSA-SSD/PF-probe was higher than that of the HSA-SSD/PF mixtures. It is particularly noteworthy that the $K_{a}$ of the HSA-PF-probe mixture significantly increased up to the order of $10^{5}$. These results indicate that SSD/PF, especially PF, promotes the affinity among the ternary complex. Recent observations indicate that warfarin has one high-affinity binding site and several low-affinity binding sites in serum albumin although numerous studies have focused on the high-affinity interaction [39]. Similarly, the decreased binding of ibuprofen is mainly attributed to the competition of low-affinity binding sites of HSA in the presence of acetonitrile [32].This implies that competitive binding most likely occurs at the low-affinity binding sites of HSA. In brief, our site-competitive experiments reveals that both SSD and PF are able to share a common binding site in HSA with warfarin and ibuprofen, namely sites I and II. PF at $10 \mu \mathrm{M}$ has no binding to site II and ibuprofen at 0-25 $\mu \mathrm{M}$ [24]. The results from high-performance affinity chromatography demonstrate that paeonol interacts with Sudlow site II on HSA [29]. This difference is probably related to experimental conditions, reaction system, or concentrations of PF.
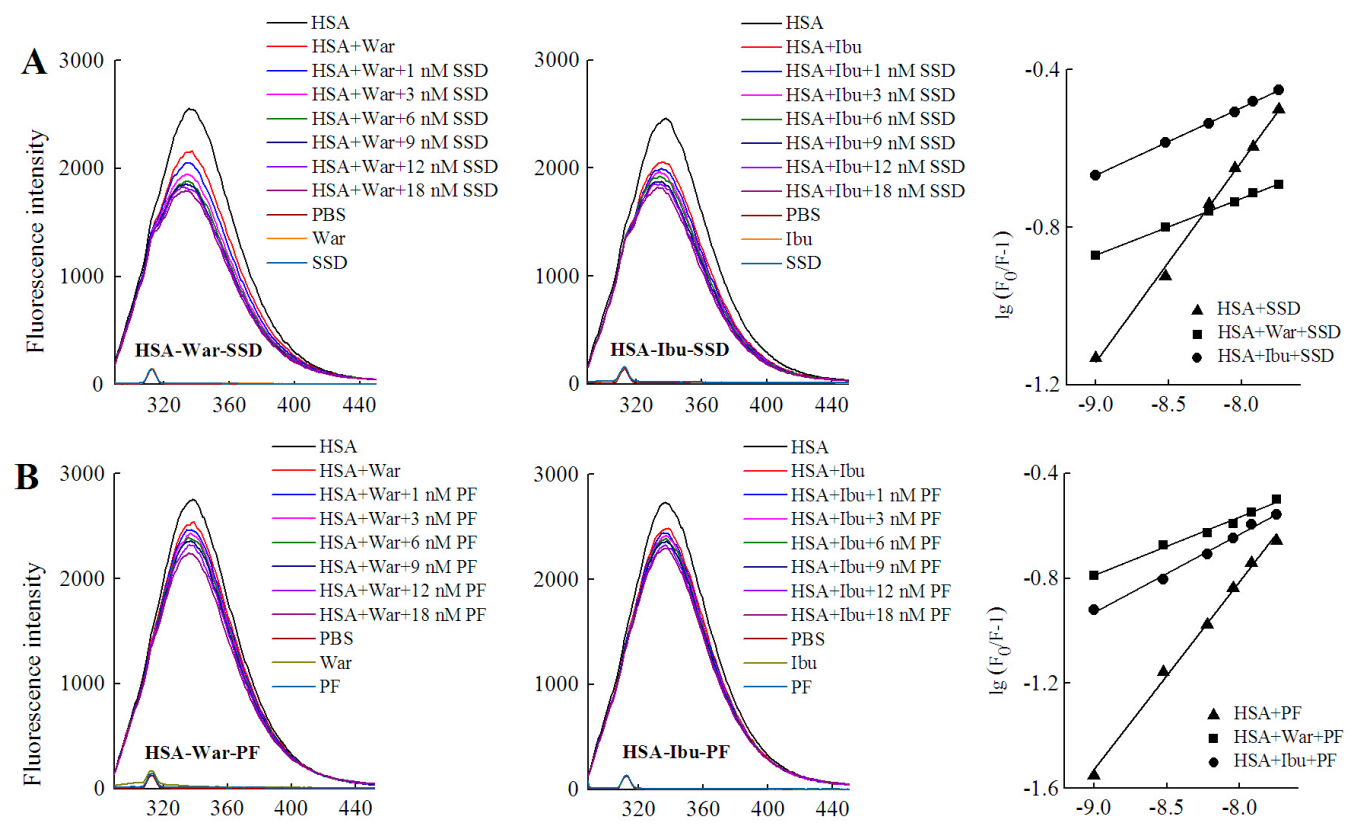

Figure 7. Cont. 

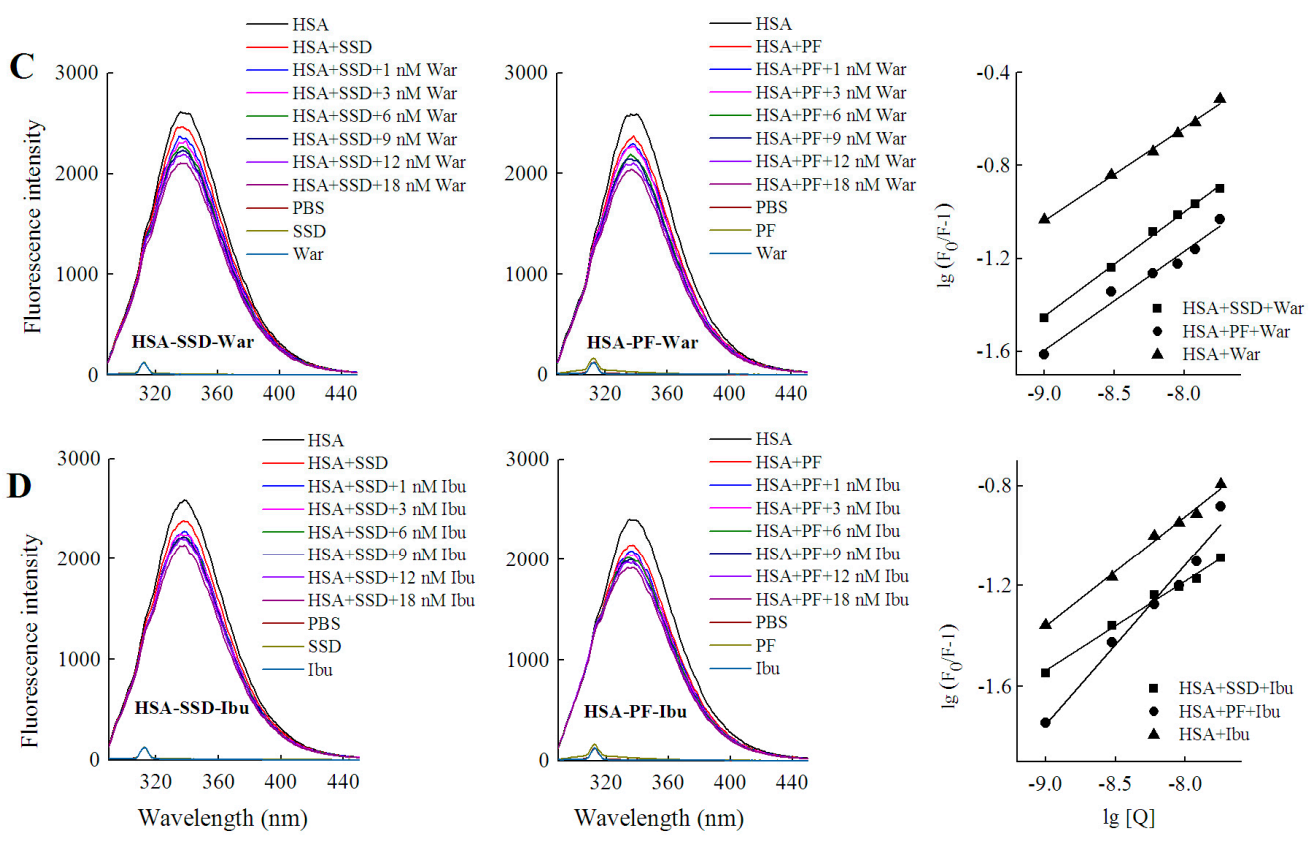

Figure 7. Effect of site marker probes on HSA-SSD and HSA-PF binding at $20{ }^{\circ} \mathrm{C}$. (A,B) stand for the competition of War/Ibu with 1-18 nM SSD/PF at $\mathrm{C}_{\mathrm{HSA}}=1 \mu \mathrm{M}, \mathrm{C}_{\mathrm{War}}=10 \mathrm{nM}, \mathrm{C}_{\mathrm{Ibu}}=184 \mathrm{nM} ;(\mathbf{C}, \mathrm{D})$ are for the competition of SSD/PF with 1-18 nM War/Ibu at $\mathrm{C}_{\mathrm{HSA}}=1 \mu \mathrm{M}, \mathrm{C}_{\mathrm{SSD}}=3 \mu \mathrm{M}, \mathrm{C}_{\mathrm{PF}}=3 \mu \mathrm{M}$; [Q], $\mathrm{C}_{\mathrm{SSD}}$ or $\mathrm{C}_{\mathrm{PF}}$ or $\mathrm{C}_{\mathrm{SSD}}$ or $\mathrm{C}_{\mathrm{SSD}}=0,1,3,6,9,12$ and $18 \mathrm{nM}$, respectively. War, Warfarin; Ibu, Ibuprofen; SSD, saikosaponin D; PF, paeoniflorin.

Table 6. Binding reaction parameters in site-competitive experiments.

\begin{tabular}{|c|c|c|c|c|c|c|}
\hline Fixed & Binding & Shift and Range (nm) & Quenching (\%) & $K_{a}\left(\mathrm{~mol} \cdot \mathrm{L}^{-1}\right) \pm \mathrm{SD}$ & $n$ & $\mathbf{R}$ \\
\hline \multirow{6}{*}{ Probe } & HSA-SSD & Left shift 5, 338-333 & 26.55 & $6.54 \times 10^{3} \pm 0.146$ & 0.525 & 0.998 \\
\hline & HSA-War-SSD & Left 5, 337-332 & 29.93 & $3.18 \pm 0.016$ & 0.224 & 0.995 \\
\hline & HSA-Ibu-SSD & Left $5,338-333$ & 26.12 & $8.42 \pm 0.025$ & 0.177 & 0.992 \\
\hline & HSA-PF & Left shift 3, 337-334 & 19.42 & $7.39 \times 10^{4} \pm 0.174$ & 0.736 & 0.998 \\
\hline & HSA-War-PF & Left $3,338-335$ & 18.57 & $3.45 \pm 0.036$ & 0.277 & 0.997 \\
\hline & HSA-Ibu-PF & Left 2, 336-334 & 16.09 & $7.86 \pm 0.039$ & 0.382 & 0.994 \\
\hline \multirow{6}{*}{$\mathrm{SSD} / \mathrm{PF}$} & HSA-War & Left 3, 338-335 & 19.07 & $2.54 \times 10^{2} \pm 0.899$ & 0.389 & 0.996 \\
\hline & HSA-PF-War & Left $4,340-336$ & 14.78 & $4.11 \times 10^{5} \pm 3.420$ & 0.716 & 0.997 \\
\hline & HSA-SSD-War & Left $4,339-335$ & 17.00 & $9.72 \times 10^{2} \pm 0.448$ & 0.469 & 0.996 \\
\hline & HSA-Ibu & Left 3, 338-335 & 17.07 & $4.10 \times 10^{2} \pm 0.169$ & 0.448 & 0.992 \\
\hline & HSA-SSD-Ibu & Left $1,335-334$ & 17.08 & $7.21 \times 10^{3} \pm 0.368$ & 0.520 & 0.994 \\
\hline & HSA-PF-Ibu & Left $3,338-335$ & 19.36 & $4.2 \times 10^{5} \pm 0.034$ & 0.638 & 0.992 \\
\hline
\end{tabular}

This study was carried out at $20^{\circ} \mathrm{C}$. $\lambda \mathrm{ex}=280 \mathrm{~nm} ; n$, number of binding sites; SD, standard deviation.

Warfarin (an anticoagulant) is widely used in cardiovascular, cerebrovascular, and other thrombotic accidents [40]. Ibuprofen (a classical anti-inflammatory drug) and its derivatives are also among the most commonly prescribed drugs in the world [41]. As a well-known couplet medication, the combination of Chai Hu with Shao Yao is often prescribed for digestive, gynecological, cardiovascular, and cerebrovascular disease [4,42,43]. Inevitably, the combination of SSD/Chai Hu or $\mathrm{PF} /$ Shao Yao often occurs clinically with warfarin- or ibuprofen-class drugs. As an excellent carrier, HSA plays an important role in the release of free drugs. Free drugs are responsible for pharmacological activities [26]. As shown in Table 5, both the $K_{a}$ of the ternary mixture for warfarin and ibuprofen can be much lower than that of HSA-SSD or -PF binding, suggesting that the concentrations of free SSD or $\mathrm{PF}$ will be greatly elevated when the two medicinal herbs are simultaneously combined with warfarin or ibuprofen. In other words, the effect of SSD/Chai Hu or PF/ Shao Yao is likely strengthened when these drugs are co-administered at the same time. 


\subsubsection{Binding Forces between HSA and SSD/PF}

In a thermodynamic process, enthalpy change $(\Delta H)$ and entropy change $(\Delta S)$ act as the mainstay to judge their binding force. The major forces of interaction between HSA and drugs include hydrogen bonds, van der Waals forces, electrostatic forces and hydrophobic interactions. The relations of thermodynamic parameters and binding forces are as follows: $\Delta H<0$ and $\Delta S<0$ illustrates the formation of hydrogen bonding or van der Waals forces, $\Delta H<0$ and $\Delta S>0$ indicates an electrostatic force, and $\Delta H>0$ and $\Delta S>0$ indicates hydrophobic interaction [44,45]. When $\Delta \mathrm{H}$ has no obvious change with temperature, the related parameters can be calculated by the following equations [30]:

$$
\begin{gathered}
\ln K_{\alpha}=-\Delta H / R T+\Delta S / R \\
\Delta G=-R T \ln K_{a} \\
\Delta G=\Delta H-T \Delta S
\end{gathered}
$$

Here, $K_{a}$ is the binding constant calculated by Equation (4), and $R$ is the gas constant, equaling $8.314 \mathrm{~J} \cdot \mathrm{K}^{-1} \cdot \mathrm{mol}^{-1}[46,47]$. As shown in Table $7, \Delta H, \Delta S$ and free energy change $(\Delta G)$ are all negative. The negative $\Delta G$ indicates that the binding is spontaneous. The present negative values of both $\Delta H$ and $\Delta S$ reveal that hydrogen bonds and van der Waals interactions play a major role in the thermodynamic process. A previous report by Yu et al. that the main force between paeonol and HSA is hydrogen bonding or van der Waals forces may support our current results (Table 5). Unlike to our partial findings, $\Delta H<0$ and $\Delta S>0$ occurs in the interaction of HSA at high concentrations with PF (Table 5). According to its thermodynamic and docking data, the study explains that HSA-PF binding is dominated by hydrophobic forces as well as hydrogen bonding. This is completely identical to the results of Wen et al. [34], who reported that hydrophobic forces $(\Delta H>0$ and $\Delta S>0)$ are responsible for HSA-PF associations (Table 5). Clearly, this needs to be further investigated in order to understand the reason for this discrepancy. Similar to SSD, the value of $\Delta G, \Delta H, \Delta S$ for SSC-HSA binding are all negative, meaning that SSC-HSA association is mainly driven by hydrogen bonding and van der Waal

\begin{tabular}{|c|c|c|c|c|c|c|c|c|}
\hline Binding & $\mathrm{T}\left({ }^{\circ} \mathrm{C}\right)$ & $\begin{array}{c}\Delta G \\
\left(\mathrm{~kJ} \cdot \mathrm{mol}^{-1}\right)\end{array}$ & $\begin{array}{c}\Delta S \\
\left(\mathrm{~J} \cdot \mathrm{mol}^{-1} \cdot \mathrm{K}^{-1}\right)\end{array}$ & $\begin{array}{c}\Delta H \\
\left(\mathrm{~kJ} \cdot \mathrm{mol}^{-1}\right)\end{array}$ & $\begin{array}{c}J \\
\left(\mathrm{~cm}^{3} \cdot \mathrm{L} \cdot \mathrm{mol}^{-1}\right)\end{array}$ & $R_{0}(\mathrm{~nm})$ & $E(\mathrm{~J})$ & $r(\mathrm{~nm})$ \\
\hline \multirow{4}{*}{ HSA-SSD } & 20 & -19.33 & \multirow{4}{*}{-314.92} & \multirow{4}{*}{-111.60} & $1.03 \times 10^{-14}$ & 2.50 & 0.24 & 3.00 \\
\hline & 23 & -17.44 & & & $1.03 \times 10^{-14}$ & 2.47 & 0.21 & 3.07 \\
\hline & 27 & -16.45 & & & $1.04 \times 10^{-14}$ & 2.06 & 0.13 & 2.83 \\
\hline & 30 & -16.18 & & & $1.04 \times 10^{-14}$ & 2.47 & 0.27 & 2.92 \\
\hline \multirow{4}{*}{ HSA-PF } & 20 & -27.64 & \multirow{4}{*}{-1201.16} & \multirow{4}{*}{-379.58} & $1.88 \times 10^{-15}$ & 1.86 & 0.05 & 2.27 \\
\hline & 23 & -22.19 & & & $1.91 \times 10^{-15}$ & 2.02 & 0.08 & 3.02 \\
\hline & 27 & -21.29 & & & $1.91 \times 10^{-15}$ & 2.05 & 0.12 & 2.85 \\
\hline & 30 & -15.63 & & & $1.92 \times 10^{-15}$ & 1.86 & 0.23 & 2.27 \\
\hline
\end{tabular}
forces (Table 5).

Table 7. Thermodynamic and energy transfer parameters.

\subsection{Energy Transfer Resulting from HSA-SSD and HSA-PF Interaction}

In this study, the process conformed to three conditions of Förster dipole-dipole non-radiative energy transfer theory. First, HSA served as an endogenous fluorescence donor. Second, there was overlap, to some extent, between the fluorescence emission spectra of the donor and the UV-vis absorbance spectra of the acceptor. Last, HSA and drug were close enough that the largest distance between them was less than $7 \mathrm{~nm}$. Accordingly, HSA-SSD/PF binding involved non-radiative energy transfer, leading to fluorescence quenching. The energy transfer $(E)$ is described by Equation (8) [25]:

$$
E=1-\frac{F}{F 0}=\frac{R_{0}^{6}}{R_{0}^{6}+r^{6}}
$$


Here, $F_{0}$ and $F$ represent the fluorescence intensity of HSA with and without SSD/PF, respectively. The $r$ is the distance between donor (HSA) and acceptor (SSD/PF), and $R_{0}$ is the critical distance when the efficiency of energy transfer is 50\% [25]. $R_{0}$ is given by Equation (9) [46]:

$$
R_{0}^{6}=8.79 \times 10^{-25} K^{2} N^{-4} \phi J
$$

There, $K^{2}$ is the dipole spatial orientation factor, $K^{2}=2 / 3 . N$ is the refractive index of the medium, equal to the average value of water and organic matter. $\varphi$ represents the fluorescence quantum yield of the donor. In the present work, $K^{2}=2 / 3$, and $N=1.336 . \varphi=0.118$ [47]. $J$ is the overlap integral between the fluorescence emission spectrum of the donor and the absorption spectrum of the acceptor, as calculated by Equation (10) [48]:

$$
J=\frac{\sum F(\lambda) \varepsilon(\lambda) \lambda^{4} \Delta \lambda}{\sum F(\lambda) \Delta \lambda}
$$

Here, $F(\lambda)$ is the fluorescence intensity of the donor and the molar absorption of the acceptor at wavelength $\lambda$, respectively. $J$ can be obtained by integrating the spectra in Figure 8 . Then, $R_{0}, E$ and $r$ can be worked out. Table 7 shows that all $r$ values were between 2 and $7 \mathrm{~nm}$, and $0.5 R_{0}<r<1.5 R_{0}$, which is in accordance with non-radioactive energy transfer theory [25]. This may explain why the fluorescence of HSA was accompanied by quenching with the efficient energy transfer in the interaction of HSA with SSD/PF. In line with the present finding, the previous study also suggests the occurrence of fluorescence energy transfer [24].
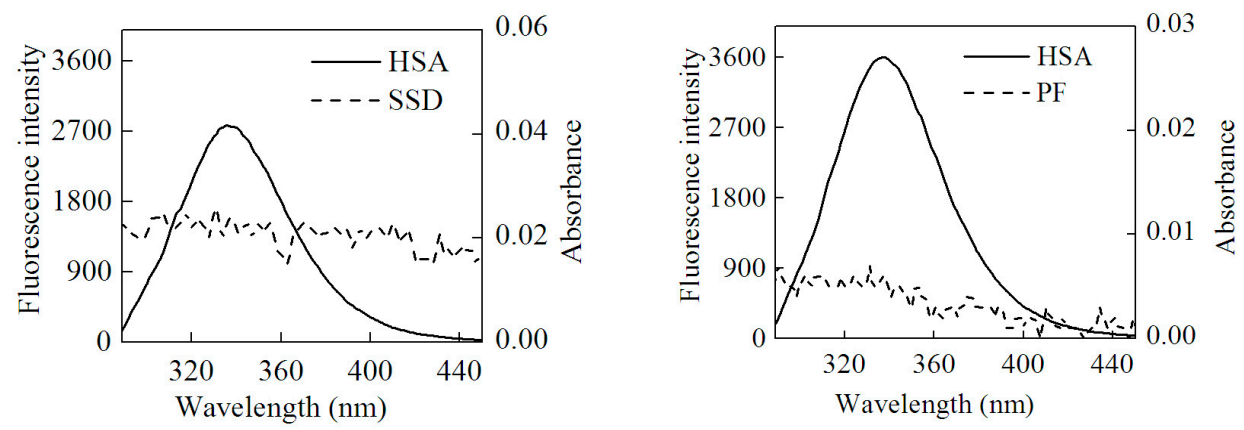

Figure 8. Overlap of the UV absorption spectra of SSD/PF and the fluorescence emission spectra of HSA.

\subsection{Molecular Docking Studies}

HSA has a single tryptophan (Trp214) located in site I. As shown in Figure 2, the quenching of PF-mediated HSA is lower than SSD-mediated quenching, suggesting that the HSA-PF binding site is not located at Trp214. To investigate this and the theoretical binding data, molecular docking was employed. Based on the information provided by the PBD databank, SSD was docked to HSA. Seven hydrogen bonds were formed between SSD and site I, site II, and the IIA-IIB binding site of HSA (Figure 9 and Table 8).

Among these, one hydrogen bond was observed between the Trp214 residue in binding site I and SSD, the pocket of which was surrounded by residues Tyr150 and Tyr452. Additionally, eleven hydrogen bonds were formed between PF and HSA sites I, II, and IIA-IIB. Hydrogen bonds were not found between PF and tyrosine/tryptophan residues although the pocket was surrounded by Trp214 and Tyr150 in site I, and Tyr411, and Trp214 in site IIA-IIB. This is perhaps a reason why the effect of SSD on the quenching of HSA is slightly higher than that of PF. In short, SSD directly binds Trp214, whereas PF does not directly bind to Trp or Tyr. Consistent with the thermodynamic observations, the docking studies demonstrate that hydrogen bonds play a major role in the binding process and the stability of HSA-SSD or -PF complexes. The experimental and docking results both disclose that $\mathrm{SSD} / \mathrm{PF}$ is mainly docked to sites I and II. 


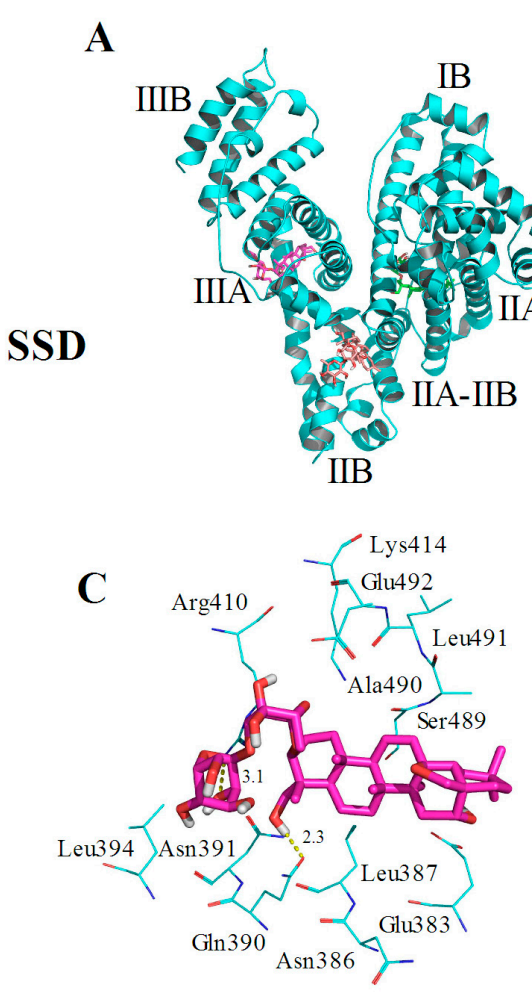

A
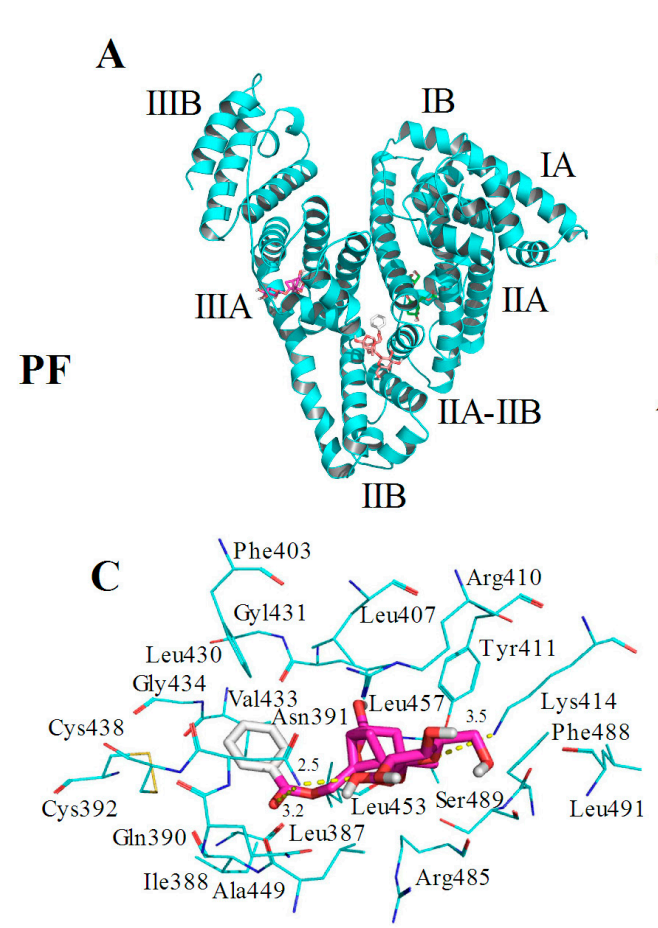
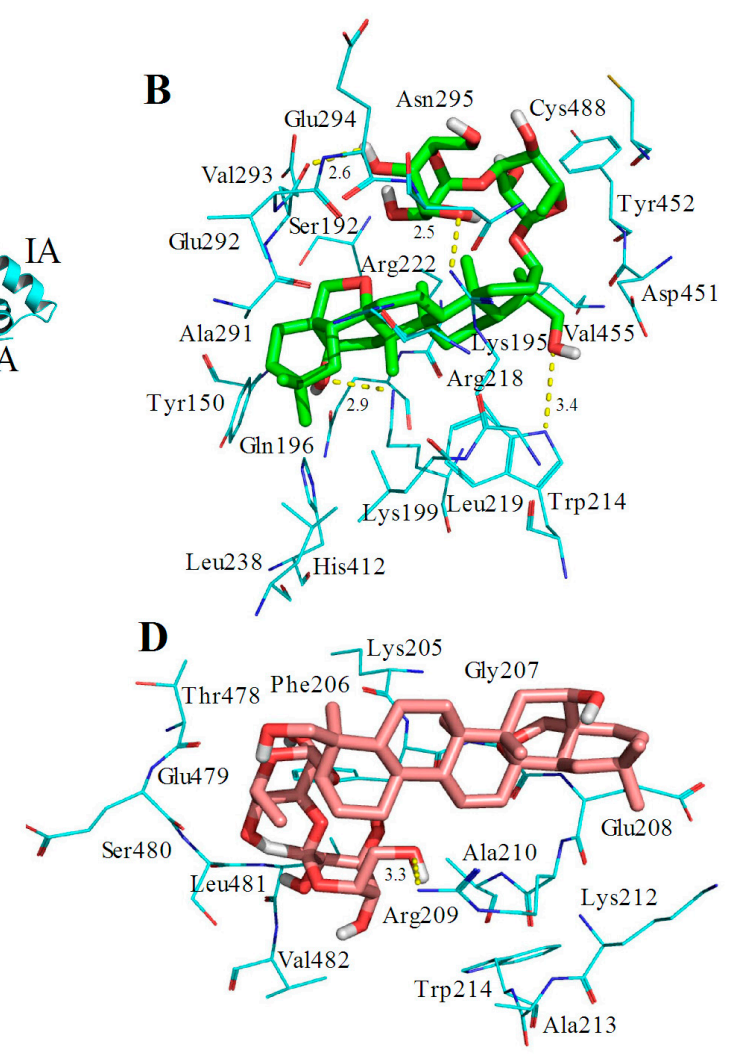
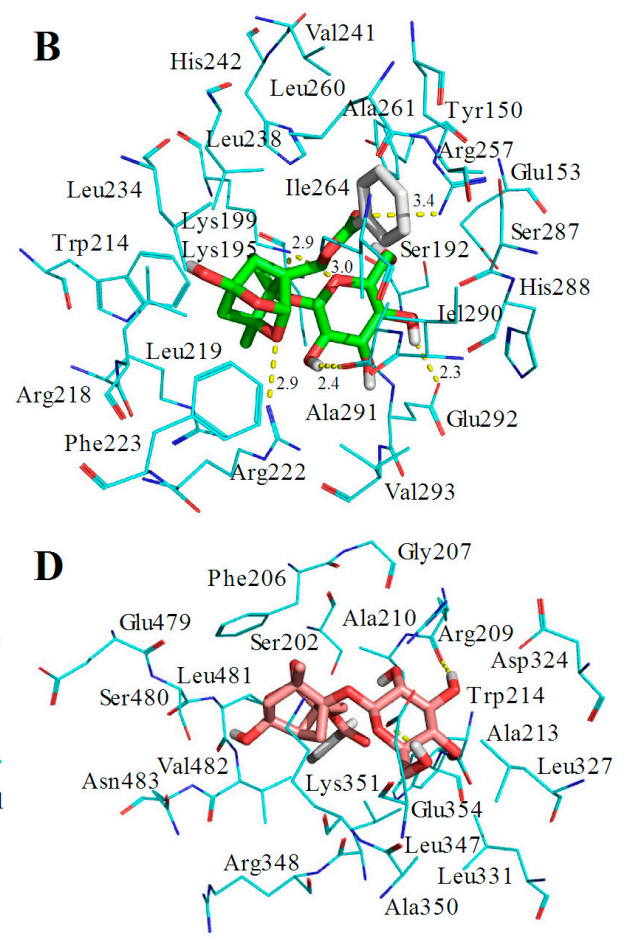

Figure 9. Optimal binding conformation of the SSD/PF-HSA complex (A). Amino acid residues of site I (B), site II (C) or the IIA-IIB site (D) surrounding SSD within $4 \AA$. The cyan structure represents HSA, the green, pink or brown stands for SSD/PF, and the yellow dotted line stands for hydrogen bonding. 
Table 8. Atoms and amino acid residues involved in hydrogen bonds formed between HSA and SSD/PF.

\begin{tabular}{|c|c|c|c|c|c|}
\hline & Site & Amino Acid Residue & Atoms * & Bond Length & $\begin{array}{c}\text { Trp or Tyr around } \\
\text { the Pocket }\end{array}$ \\
\hline \multirow{7}{*}{ SSD } & \multirow{4}{*}{ Site I } & Lys199 & $\mathrm{CH}_{2} \mathrm{OH}(7)$ & $2.9 \AA$ & \multirow{4}{*}{$\begin{array}{l}\text { Tyr150 } \\
\text { Tyr452 }\end{array}$} \\
\hline & & Trp214 & $\mathrm{CH}_{2} \mathrm{CH}_{2} \mathrm{OH}(24)$ & $3.4 \AA$ & \\
\hline & & Arg218 & $\mathrm{CH}_{2} \mathrm{OH}(35)$ & $2.5 \AA$ & \\
\hline & & Glu292 & $\mathrm{CH}_{2} \mathrm{OH}(36)$ & $2.6 \AA$ & \\
\hline & \multirow{2}{*}{ Site II } & Asn391 & $\mathrm{CH}_{2} \mathrm{CH}_{2} \mathrm{OH}(24)$ & $2.3 \AA$ & \multirow{2}{*}{ Trp214 } \\
\hline & & Arg410 & $\mathrm{CH}_{2} \mathrm{OH}(34)$ & $3.1 \AA$ & \\
\hline & IIA-IIB & Arg209 & $\mathrm{CH}_{2} \mathrm{CH}_{2} \mathrm{OH}$ (37) & $3.3 \AA$ & \\
\hline \multirow{11}{*}{$\mathrm{PF}$} & \multirow{6}{*}{ Site I } & Lys199 & $\mathrm{O}(21)$ & $2.9 \AA$ & \multirow{6}{*}{$\begin{array}{l}\text { Tyr150 } \\
\text { Trp214 }\end{array}$} \\
\hline & & Lys199 & $\mathrm{O}(27)$ & $3.0 \AA$ & \\
\hline & & Arg257 & $\mathrm{O}(14)$ & $3.4 \AA$ & \\
\hline & & Arg218 & $\mathrm{CH}_{2} \mathrm{OH}(25)$ & $2.3 \AA$ & \\
\hline & & Ala291 & $\mathrm{CH}_{2} \mathrm{OH}(23)$ & $2.4 \AA$ & \\
\hline & & Glu292 & $\mathrm{O}(10)$ & $2.9 \AA$ & \\
\hline & \multirow{3}{*}{ Site II } & Asn391 & $\mathrm{O}(14)$ & $3.2 \AA$ & \multirow{3}{*}{ Trp214 } \\
\hline & & Asn391 & $\mathrm{CH}_{2} \mathrm{OH}(23)$ & $2.5 \AA$ & \\
\hline & & Lys414 & $\mathrm{O}(27)$ & $3.5 \AA$ & \\
\hline & \multirow{2}{*}{ IIA-IIB } & Arg209 & $\mathrm{CH}_{2} \mathrm{OH}(24)$ & $2.2 \AA$ & \multirow{2}{*}{ Tyr411 } \\
\hline & & Glu354 & $\mathrm{CH}_{2} \mathrm{CH}_{2} \mathrm{OH}(26)$ & $2.0 \AA$ & \\
\hline
\end{tabular}

Moreover, SSD/PF is also docked to the interface between sub-domain IIA-IIB, which suggests that the potential binding site may have little effect on the allosteric nature of HAS-SSD/PF binding. Out of these sites, site I is likely to be the most preferred, based on the findings of docking and site-competitive binding. In the previous model, PF is also docked to site I [21]. There is no evidence in the current study yet to show the probability for the competitive binding of SSD/PF to HSA with warfarin or ibuprofen at site IIA-IIB, although the model study points out the potential allosteric nature of SSD/PF. In a word, these results indicate that docking analysis supports a structural basis for the HSA-SSD or -PF interaction.

\section{Materials and Methods}

\subsection{Materials}

HSA (96.0\% purity by electrophoresis), tyrosine and tryptophan (both $98.0 \%$ purity by TLC) were purchased from Sigma (St. Louis, MO, USA). Commercial prepared SSD and PF (98.0\% purity by HPLC) was acquired from Biopurify Phytochemical Ltd. (Chengdu, Sichuan, China). Ibuprofen and warfarin (both 99.7\% purity) were purchased from the National Institute for Drug Control (Beijing, China). All other reagents were analytically pure grade.

\subsection{Absorbance Measurements}

The UV-visible absorption spectrum was recorded at room temperature on a NanoDrop 2000c spectrophotometer (Thermo, Waltham, MA, USA) equipped with quartz cells.

\subsection{Fluorescence Spectra}

All fluorescence measurements were recorded on an F-7000 spectrofluorometer (Hitachi, Tokyo, Japan). For conventional fluorescence measurements, the width of the excitation and emission slit were fixed at $2.5 \mathrm{~nm}$ and scan speed at $1200 \mathrm{~nm}$ per minute and an excitation wavelength at $280 \mathrm{~nm}$ [25]. HSA at $1 \mu \mathrm{M}$ was dissolved in $0.01 \mathrm{M}$ phosphate-buffered saline (PBS), $\mathrm{pH} 7.4$, added to the quartz cell, and then titrated with a $3 \mu \mathrm{M}$ solution of SSD/PF to reach a concentration of 0 to $18 \mathrm{nM}$ at $20^{\circ} \mathrm{C}\left(=293{ }^{\circ} \mathrm{K}\right)$ and $30^{\circ} \mathrm{C}\left(=303^{\circ} \mathrm{K}\right)$. For synchronous fluorescence measurements, the excitation and 
emission slit were fixed at $2.5 \mathrm{~nm}$ and the scan speed set at $240 \mathrm{~nm}$ per minute. Data were collected with a $\Delta \lambda=15 \mathrm{~nm}$ for tyrosine and $\Delta \lambda=60 \mathrm{~nm}$ for tryptophan residues. In the ternary interaction experiments, following $3 \mu \mathrm{M}$ PF addition to $1 \mu \mathrm{M}$ HSA, the solution was titrated with $3 \mu \mathrm{M}$ SSD. The converse experiment was also performed where PF was used to titrate the solution following $3 \mu \mathrm{M}$ SSD addition to a $1 \mu \mathrm{M}$ HSA solution. In the site-competitive study, $10 \mathrm{nM}$ warfarin or $184 \mathrm{nM}$ ibuprofen was dissolved in $3 \mathrm{~mL}$ of HSA at $1 \mu \mathrm{M}$. Then, a SSD/PF solution was successively titrated as indicated in the text. The converse site-competitive experiment was also performed [24,49]. In brief, the concentration of HSA and SSD/PF was fixed at $1 \mu \mathrm{M}$ and $3 \mu \mathrm{M}$, respectively, followed by the titration of $3 \mu \mathrm{M}$ warfarin or $3 \mu \mathrm{M}$ ibuprofen. For the direct interaction experiments, $3.0 \mathrm{~mL}$ solutions of tyrosine or tryptophan at $10 \mu \mathrm{M}$ were titrated by successive additions of $3 \mu \mathrm{M} \mathrm{SSD} / \mathrm{PF}$ solution.

\subsection{Correction of the Internal Filter}

In order to avoid an inner filter effect, all fluorescence data was corrected using the following formula [25]:

$$
F_{\text {cor }}=F_{\text {obs }} \times 10^{\left(A_{\mathrm{ex}}+A_{\mathrm{em}}\right) / 2}
$$

Here, $F_{c o r}$ and $F_{o b s}$ are the fluorescence intensities of the solution after and before the correction. $A_{e x}$ and $A_{e m}$ are the absorbances of the solution at the excitation and emission wavelengths, respectively.

\subsection{Spectra}

CD spectra of HSA in the absence and presence of SSD/PF were measured by a MOS 450 automatic spectropolarimeter (BioLogic Science Instruments, Claix, France). HSA at a concentration of $1 \mu \mathrm{M}$ was used. The ratio of HSA, SSD and PF was 1:1:1. A scan rate was set as $30 \mathrm{~nm}$ per minute with a response time of $4 \mathrm{~s}$.

\subsection{Molecular Docking}

The three-dimensional coordinates of HSA (PDB ID: 2BXA for SSD; 2BXE for PF) were downloaded from the Protein Data Bank (http://www.rcsb.org/pdb) [50]. The docking input files were produced by The Auto Dock Tools software version 1.5.6 (http://mgltools.scripps.edu). Ligand structures were prepared for docking by merging non-polar hydrogen atoms and defining rotatable bonds. The value of exhaustiveness was set to 20 to promote docking accuracy. For Vina docking, the default parameters were used as described in the Autodock Vina manual unless otherwise specified. The top ranked conformation, as judged by the Vina docking score, was subject to visual analysis by using PyMOL 1.7 software (http:/ / www.pymol.org).

\section{Conclusions}

Both SSD and PF can dose-dependently quench the intrinsic fluorescence of HSA by a static mechanism. Co-binding of SSD with PF also produced a quenching effect on HSA, accompanied by a blue shift of the spectra. The Stern-Volmer constant for HSA-SSD or HSA-PF binding with a low affinity is inversely correlated with temperature. The negative value of $\Delta G, \Delta H$, and $\Delta S$ indicate that the binding process occurs spontaneously, and is mainly driven by hydrogen bonds and Van der Waals forces. There is a non-radiation energy transfer based on the Förster theory. Experimental site-competitive studies suggest that SSD or PF can bind to site I and II of HSA. These results obtained from synchronous fluorescence and CD spectroscopy demonstrate that SSD or PF are able to change the conformation of HSA when they interact. Docking studies support the experimental and calculated data for conformational change, binding site and binding force induced by SSD or PF. In addition, SSD or PF can also be docked to the interface between site IIA-IIB. 
Acknowledgments: This work was supported by the grants from the National Natural Science Foundation of China (No. 81573820, 2015 and 81072941, 2010), Science \& Technology Program of Guangdong (No. 2016B090918129), Natural Science Foundation of Guangdong province (2015A030313432), and Science \& Technology Program of Shantou (No. 2015-132-105).

Author Contributions: Yi-Cun Chen and Qing-Xia Niu designed the study. Guo-Wu Liang, Hong-Mei Wang, Yi Wang, and Xiang-Yu Pan analyzed the data. Qing-Xia Niu and Guo-Wu Liang wrote the paper. Yi Wang and Pei-Hong Chen were mainly responsible for molecular docking. All authors performed the experiments, discussed the results, and approved the manuscript. Guo-Wu Liang and Yi-Cun Chen contributed equally.

Conflicts of Interest: The authors declare no conflict of interest.

\section{References}

1. Zunszain, P.A.; Ghuman, J.; Komatsu, T.; Tsuchida, E.; Curry, S. Crystal structural analysis of human serum albumin complexed with hemin and fatty acid. BMC. Struct. Biol. 2003, 3, 6-15. [CrossRef] [PubMed]

2. Curry, S.; Mandelkow, H.; Brick, P.; Franks, N. Crystal structure of human serum albumin complexed with fatty acid reveals an asymmetric distribution of binding sites. Nat. Struct. Biol. 1998, 5, 827-835. [CrossRef] [PubMed]

3. Bal, W.; Sokolowska, M.; Kurowska, E.; Faller, P. Binding of transition metal ions to albumin: Sites, affinities and rates. Biochim. Biophys. Acta 2013, 1830, 5444-5455. [CrossRef] [PubMed]

4. Yuan, B.; Yang, R.; Ma, Y.; Zhou, S.; Zhang, X.; Liu, Y. A systematic review of the active saikosaponins and extracts isolated from Radix Bupleuri and their applications. Pharm. Biol. 2017, 55, 620-635. [CrossRef] [PubMed]

5. Yang, F.; Dong, X.; Yin, X.; Wang, W.; You, L.; Ni, J. Radix bupleuri: A review of traditional uses, botany, phytochemistry, pharmacology, and toxicology. Biomed. Res. Int. 2017, 2017, 7597596. [CrossRef] [PubMed]

6. Guan, X.; Wang, X.; Yan, K.; Chu, Y.; Li, S.; Li, W.; Yan, X.; Ma, X.; Zhou, S.; Sun, H.; Liu, C. UFLC-MS/MS determination and pharmacokinetic studies of six saikosaponins in rat plasma after oral administration of bupleurum dropping pills. J. Pharm. Biomed. Anal. 2016, 124, 288-293. [CrossRef] [PubMed]

7. Lu, C.N.; Yuan, Z.G.; Zhang, X.L.; Yan, R.; Zhao, Y.Q.; Liao, M.; Chen, J.X. Saikosaponin a and its epimer saikosaponin d exhibit anti-inflammatory activity by suppressing activation of NF-kappaB signaling pathway. Int. Immunopharmacol. 2012, 14, 121-126. [CrossRef] [PubMed]

8. Zhang, B.Z.; Guo, X.T.; Chen, J.W.; Zhao, Y.; Cong, X.; Jiang, Z.L.; Cao, R.F.; Cui, K.; Gao, S.S.; Tian, W.R. Saikosaponin-D attenuates heat stress-induced oxidative damage in LLC-PK1 cells by increasing the expression of anti-oxidant enzymes and HSP72. Am. J. Chin. Med. 2014, 42, 1261-1277. [CrossRef] [PubMed]

9. Fan, J.; Li, X.; Li, P.; Li, N.; Wang, T.; Shen, H.; Siow, Y.; Choy, P.; Gong, Y. Saikosaponin-d attenuates the development of liver fibrosis by preventing hepatocyte injury. Biochem. Cell Biol. 2007, 85, 189-195. [CrossRef] [PubMed]

10. Dang, S.S.; Wang, B.F.; Cheng, Y.A.; Song, P.; Liu, Z.G.; Li, Z.F. Inhibitory effects of saikosaponin-d on CCl4-induced hepatic fibrogenesis in rats. World J. Gastroenterol. 2007, 13, 557-563. [CrossRef] [PubMed]

11. Chen, M.F.; Huang, S.J.; Huang, C.C.; Liu, P.S.; Lin, K.I.; Liu, C.W.; Hsieh, W.C.; Shiu, L.Y.; Chen, C.H. Saikosaponin $\mathrm{d}$ induces cell death through caspase-3-dependent, caspase-3-independent and mitochondrial pathways in mammalian hepatic stellate cells. BMC. Cancer 2016, 16, 532-544. [CrossRef] [PubMed]

12. Wang, Q.; Yang, H.; Liu, W.; Feng, X.; Zhang, L.; Li, Y.; Bi, K.; Guo, D. Determination of paeoniflorin in rat plasma by a liquid chromatography-tandem mass spectrometry method coupled with solid-phase extraction. Biomed. Chromatogr. 2006, 20, 173-179. [CrossRef] [PubMed]

13. Song, S.; Xiao, X.; Guo, D.; Mo, L.; Bu, C.; Ye, W.; Den, Q.; Liu, S.; Yang, X. Protective effects of paeoniflorin against AOPP-induced oxidative injury in HUVECs by blocking the ROS-HIF-1alpha/VEGF pathway. Phytomedicine 2017, 34, 115-126. [CrossRef] [PubMed]

14. Zhao, Y.; Ma, X.; Wang, J.; Zhu, Y.; Li, R.; Wang, J.; He, X.; Shan, L.; Wang, R.; Wang, L.; et al. Paeoniflorin alleviates liver fibrosis by inhibiting HIF-1alpha through mTOR-dependent pathway. Fitoterapia 2014, 99, 318-327. [CrossRef] [PubMed]

15. Ma, Z.; Chu, L.; Liu, H.; Wang, W.; Li, J.; Yao, W.; Yi, J.; Gao, Y. Beneficial effects of paeoniflorin on non-alcoholic fatty liver disease induced by high-fat diet in rats. Sci. Rep. 2017, 7, 44819-44829. [CrossRef] [PubMed] 
16. Gu, P.; Zhu, L.; Liu, Y.; Zhang, L.; Liu, J.; Shen, H. Protective effects of paeoniflorin on TNBS-induced ulcerative colitis through inhibiting NF-kappaB pathway and apoptosis in mice. Int. Immunopharmacol. 2017, 50, 152-160. [CrossRef] [PubMed]

17. Wang, Y.; Zhang, H.; Kang, Y.; Cao, J. Effects of perfluorooctane sulfonate on the conformation and activity of bovine serum albumin. J. Photochem. Photobiol. B Biol. 2016, 159, 66-73. [CrossRef] [PubMed]

18. Pastukhov, A.V.; Levchenko, L.A.; Sadkov, A.P. Spectroscopic study on binding of rutin to human serum albumin. J. Mol. Struct. 2007, 842, 60-66. [CrossRef]

19. Yamasaki, K.; Hyodo, S.; Taguchi, K.; Nishi, K.; Yamaotsu, N.; Hirono, S.; Chuang, V.T.G.; Seo, H.; Maruyama, T.; Otagiri, M. Long chain fatty acids alter the interactive binding of ligands to the two principal drug binding sites of human serum albumin. PLoS ONE 2017, 12, e0180404. [CrossRef] [PubMed]

20. Alanazi, A.M.; Abdelhameed, A.S. A spectroscopic approach to investigate the molecular interactions between the newly approved irreversible ErbB blocker "Afatinib" and bovine serum albumin. PLoS ONE 2016, 11, e0146297. [CrossRef] [PubMed]

21. Wang, B.; Qin, Q.; Chang, M.; Li, S.; Shi, X.; Xu, G. Molecular interaction study of flavonoids with human serum albumin using native mass spectrometry and molecular modeling. Anal. Bioanal. Chem. 2017, 409. [CrossRef] [PubMed]

22. Zhang, W.; Chen, C.; Zhang, C.; Duan, J.; Yao, H.; Li, Y.; Meng, A.; Shi, J. Insight into the binding interaction of kaempferol-7-O-alpha-L-rhamnopyranoside with human serum albumin by multiple fluorescence spectroscopy and molecular modeling. Exp. Ther. Med. 2017, 13, 3619-3623. [CrossRef] [PubMed]

23. Laskar, K.; Alam, P.; Khan, R.H.; Rauf, A. Synthesis, characterization and interaction studies of 1,3,4-oxadiazole derivatives of fatty acid with human serum albumin (HSA): A combined multi-spectroscopic and molecular docking study. Eur. J. Med. Chem. 2016, 122, 72-78. [CrossRef] [PubMed]

24. Xu, L.; Hu, Y.X.; Li, Y.C.; Liu, Y.F.; Zhang, L.; Ai, H.X.; Liu, H.S. Study on the interaction of paeoniflorin with human serum albumin (HSA) by spectroscopic and molecular docking techniques. Chem. Cent. J. 2017, 11, 116. [CrossRef] [PubMed]

25. Lakowicz, J.R. Principles of Fluorescence Spectroscopy, 3rd ed.; Plenum Press: New York, NY, USA, 2006.

26. Chen, Y.C.; Wang, H.M.; Niu, Q.X.; Ye, D.Y.; Liang, G.W. Binding between saikosaponin C and human serum albumin by fluorescence spectroscopy and molecular docking. Molecules 2016, 21, 153-158. [CrossRef] [PubMed]

27. Szkudlarek, A.; Pentak, D.; Ploch, A.; Pozycka, J.; Maciazek-Jurczyk, M. Effect of temperature on tolbutamide binding to glycated serum albumin. Molecules 2017, 22. [CrossRef] [PubMed]

28. Hu, Y.J.; Liu, Y.; Xiao, X.H. Investigation of the interaction between berberine and human serum albumin. Biomacromolecules 2009, 10, 517-521. [CrossRef] [PubMed]

29. Yu, X.; Zhang, J.; Wei, Y. Determination of binding domains of paeonol on immobilized human serum albumin by high-performance affinity chromatography. Se Pu 2010, 28, 688-692. (In Chinese) [CrossRef] [PubMed]

30. Shi, J.H.; Zhu, Y.Y.; Wang, J.; Chen, J.; Shen, Y.J. Intermolecular interaction of prednisolone with bovine serum albumin: Spectroscopic and molecular docking methods. Spectrochim. Acta A Mol. Biomol. Spectrosc. 2013, 15, 287-294. [CrossRef] [PubMed]

31. Abdelhameed, A.S.; Bakheit, A.H.; Almutairi, F.M.; AlRabiah, H.; Kadi, A.A. Biophysical and in silico studies of the interaction between the anti-viral agents acyclovir and penciclovir, and human serum albumin. Molecules 2017, 22. [CrossRef] [PubMed]

32. Ji, Z.; Yuan, H.; Liu, M.; Hu, J. 1H-NMR study of the effect of acetonitrile on the interaction of ibuprofen with human serum albumin. J. Pharm. Biomed. Anal. 2002, 30, 151-159. [CrossRef]

33. Dasgupta, A. Clinical utility of free drug monitoring. Clin. Chem. Lab. Med. 2002, 40, 986-993. [CrossRef] [PubMed]

34. Wen, H.; Zhang, H.; Wang, Y.; Zhang, X.; Hu, P. Investigation of the inter-action between bovine serum albumin with paeoniforin and loganin. J. Pharm. Anal. 2010, 30, 6-11. (In Chinese)

35. Wang, J. Binding of paeonol to human serum albumin: A hybrid spectroscopic approach and conformational study. J. Biochem. Mol. Toxicol. 2015, 29, 213-220. [CrossRef] [PubMed]

36. Sudlow, G.; Birkett, D.J.; Wade, D.N. Further characterization of specific drug binding sites on human serum albumin. Mol. Pharmacol. 1976, 12, 1052-1061. [PubMed] 
37. Rimac, H.; Dufour, C.; Debeljak, Z.; Zorc, B.; Bojic, M. Warfarin and flavonoids do not share the same binding region in binding to the IIA subdomain of human serum albumin. Molecules 2017, 22. [CrossRef] [PubMed]

38. Yamasaki, K.; Chuang, V.T.; Maruyama, T.; Otagiri, M. Albumin-drug interaction and its clinical implication. Biochim. Biophys. Acta 2013, 1830, 5435-5443. [CrossRef] [PubMed]

39. Ni, Y.; Zhang, X.; Kokot, S. Spectrometric and voltammetric studies of the interaction between quercetin and bovine serum albumin using warfarin as site marker with the aid of chemometrics. Spectrochim. Acta A. Mol. Biomol. Spectrosc. 2009, 71, 1865-1872. [CrossRef] [PubMed]

40. Leite, P.M.; Martins, M.A.P.; Castilho, R.O. Review on mechanisms and interactions in concomitant use of herbs and warfarin therapy. Biomed. Pharmacother. 2016, 83, 14-21. [CrossRef] [PubMed]

41. De Martino, M.; Chiarugi, A.; Boner, A.; Montini, G.; De'Angelis, G.L. Working towards an appropriate use of ibuprofen in children: An evidence-based appraisal. Drugs 2017, 77, 1295-1311. [CrossRef] [PubMed]

42. Law, B.Y.; Mo, J.F.; Wong, V.K. Autophagic effects of chaihu (dried roots of bupleurum chinense DC or bupleurum scorzoneraefolium WILD). Chin. Med. 2014, 9, 21-29. [CrossRef] [PubMed]

43. Zhang, J.J.; Li, W.; Wang, L.L.; Huang, Y.F.; Wang, C.; Wang, J.X.; Huang, B.; Gao, X.M. Varieties, functions and clinical applications of chishao and baishao: A literature review. Zhongguo Zhong Yao Za Zhi 2013, 38, 3595-3601. (In Chinese) [PubMed]

44. Ross, P.D.; Subramanian, S. Thermodynamics of protein association reactions: Forces contributing to stability. Biochemistry 1981, 20, 3096-3102. [CrossRef] [PubMed]

45. Tronina, T.; Strugala, P.; Poplonski, J.; Wloch, A.; Sordon, S.; Bartmanska, A.; Huszcza, E. The influence of glycosylation of natural and synthetic prenylated flavonoids on binding to human serum albumin and inhibition of cyclooxygenases COX-1 and COX-2. Molecules 2017, 22. [CrossRef] [PubMed]

46. Ma, R.; Pan, H.; Shen, T.; Li, P.; Chen, Y.; Li, Z.; Di, X.; Wang, S. Interaction of flavonoids from Woodwardia unigemmata with bovine serum albumin (BSA): Application of spectroscopic techniques and molecular modeling methods. Molecules 2017, 22. [CrossRef] [PubMed]

47. Wang, X.; Liu, Y.; He, L.L.; Liu, B.; Zhang, S.Y.; Ye, X.; Jing, J.J.; Zhang, J.F.; Gao, M.; Wang, X. Spectroscopic investigation on the food components-drug interaction: The influence of flavonoids on the affinity of nifedipine to human serum albumin. Food Chem. Toxicol. 2015, 78, 42-51. [CrossRef] [PubMed]

48. Stryer, L. Fluorescence energy transfer as a spectroscopic ruler. Annu. Rev. Biochem. 1978, 47, 819-846. [CrossRef] [PubMed]

49. Ibrahim, N.; Ibrahim, H.; Kim, S.; Nallet, J.P.; Nepveu, F. Interactions between antimalarial indolone-N-oxide derivatives and human serum albumin. Biomacromolecules 2010, 11, 3341-3351. [CrossRef] [PubMed]

50. RCSB Protein Data Bank-Structure Summary. Available online: http://www.rcsb.org/pdb/explore/ explore.do?structureId=2BXE (accessed on 30 November 2017).

Sample Availability: Not Available.

(C) 2018 by the authors. Licensee MDPI, Basel, Switzerland. This article is an open access article distributed under the terms and conditions of the Creative Commons Attribution (CC BY) license (http:/ / creativecommons.org/licenses/by/4.0/). 